\title{
Preparation, characterization and evaluation of aspirin: benzoic acid cocrystals with enhanced pharmaceutical properties
}

\author{
Braham Dutt ${ }^{1}$, Manjusha Choudhary ${ }^{2}$ and Vikas Budhwar ${ }^{1 *}$
}

\begin{abstract}
Background: The cocrystallization process in pharmaceuticals has gained widespread attention as a recent method of modifying physicochemical properties without altering the pharmacological characteristics of drugs. Cocrystallization provides a couple of benefits like it can be employed for a large number of APIs (acidic, basic, ionizable, or non-ionizable), and secondly, the availability of a large number of potential coformers increases the possibility of the cocrystals (CCS) that can be synthesized for an API. The main objective of this study was to investigate the effects of cocrystallization on drugs having poor aqueous solubility.

Results: Aspirin (AN) and benzoic acid (BZ) were cocrystallized by using the solvent evaporation technique. CSD (Cambridge Structure Database) software and $\triangle p K a$ value method were used for the selection of the drug and coformer and for prediction of CC formation. The analysis of CCs was performed using DSC (differential scanning calorimetry), FT-IR (Fourier transformation infra-red spectroscopy) and XRD (X-ray diffraction) techniques. In vivo anti-inflammatory studies were conducted on 24 Wistar rats divided into four groups.

Conclusions: Here, in this study, in vitro dissolution studies revealed an improved solubility profile of CCs compared to pure drug and marketed formulation viz. $87 \%, 31 \%$ and $60 \%$ respectively. The in vivo antiinflammatory studies exhibited improved anti-inflammatory activity compared to pure drug. So, on the basis of outcomes of this study, we concluded that cocrystallization process have a direct impact on the improvement of physicochemical characteristics of APIs having issues like solubility or stability without any modification and alteration of their pharmacological actions.
\end{abstract}

Keywords: Cocrystallization, Aspirin, Homosynthon, Anti-inflammatory studies, Solubility

\section{Background}

It is a challenging task for pharmaceutical researchers and industry to develop suitable formulation with higher physicochemical properties. The process of cocrystallization is long known; however, in the recent times, this approach has gained

\footnotetext{
* Correspondence: vikaasbudhwar@yahoo.com

'Department of Pharmaceutical Sciences, Maharshi Dayanand University, Rohtak 124001, India

Full list of author information is available at the end of the article
}

enormous importance in pharmaceuticals as a relatively new method for enhancement of solubility, bioavailability, stability, thermal properties, permeability, tabletability and other related physicochemical properties [1]. Cocrystals (CCs) are multicomponent systems in which two components, an active pharmaceutical ingredient and a coformer, are present in stoichiometric ratio and bonded together with non-covalent interactions in the crystal lattice [2]. Cocrystallization offers better

\section{Springer Open}

(0) The Author(s). 2020 Open Access This article is licensed under a Creative Commons Attribution 4.0 International License, which permits use, sharing, adaptation, distribution and reproduction in any medium or format, as long as you give appropriate credit to the original author(s) and the source, provide a link to the Creative Commons licence, and indicate if changes were made. The images or other third party material in this article are included in the article's Creative Commons licence, unless indicated otherwise in a credit line to the material. If material is not included in the article's Creative Commons licence and your intended use is not permitted by statutory regulation or exceeds the permitted use, you will need to obtain permission directly from the copyright holder. To view a copy of this licence, visit http://creativecommons.org/licenses/by/4.0/. 
optimization of not even physicochemical properties but also therapeutic response and pharmacological properties of APIs. The design of a cocrystallization experiment is based on robustness, hydrogen bonding rules and potential intermolecular interactions [3]. Aspirin (AN) is one of the most broadly utilized medications in the world. It was discovered as an anti-inflammatory agent in 1874 [4]. Since then, many other benefits of this drug like antipyretic, anti-platelets, and anticancer have been demonstrated in animals and humans by various researchers from time to time [5]. AN is poorly dissolvable in water and causes gastrointestinal (GI) disturbance. Orally administered AN requires high and successive dosing in light of the fact that it experiences broad presystemic metabolism [6]. Likewise, long term and chronic oral AN is related with genuine gastrointestinal symptoms. AN has been cocrystallized in numerous previous studies like drug: drug CCs of meloxicam: AN [7], AN: nicotinamide CCs [8], and pentoxifylline: AN CCs [9] showing enhanced dissolution profile, but in most of earlier studies, either AN was used as a coformer with other drugs or complete in vitro and in vivo analysis of its CCs were not performed. Here, in this study, we cocrystallized AN with BZ through the solvent evaporation method. The primary objective of this study was to evaluate the effect of cocrystallization on the solubility profile of poorly water-soluble drug. The techniques like CSD software [10] and $\Delta \mathrm{pKa}$ value [11] method were used to select the drug and coformers along with prediction of CCs formation. The cocrystallization was completed in a fixed stoichiometric ratio of 1:1 for both drug and coformer respectively. The purity analysis of drug and characterization of drug, coformer, their physical mixture (PM) and CCs were performed using DSC, FT-IR and XRD techniques. In vitro dissolution and in vivo anti-inflammatory studies were conducted to analyse the drug release profile of drug, $\mathrm{CCs}$ and marketed formulation. In most of previous studies, Wistar rats animal species were used for in vivo anti-inflammatory studies. The outcomes of this study revealed an enhanced dissolution profile and a better anti-inflammatory response of CCs compared to the pure drug.

\section{Methods}

AN was purchased from Loba Chemie Pvt Ltd. (Mumbai, India). BZ was obtained from SigmaAldrich Chemical Limited, carrageenan from Central Drug House (P) Ltd. New Delhi, sodium hydroxide from Loba Chemie Pvt. Ltd., Mumbai, and all other reagents and chemicals used were of analytical grade. The solvent evaporation method was used to prepare CCs. In vivo studies were performed as per the IAEC guidelines and approval of IAEC Committee. Twenty-four Wistar rats of average body weight $180 \mathrm{~g}$ were selected from the institutional animal house. The study was approved by Institutional Animals Ethics committee [1767/GO/ Re/S/14/CPCSEA; dated: August 31, 2017]. Authors have obtained written informed consent to use the animals in the study from the institute.

\section{In vivo studies}

The animal experiments complied with the ARRIVE guidelines. The ARRIVE checklist has been attached as an additional file.

\section{Selection of drug and coformer}

The cocrystallization process basically depends upon synthon formation between two molecules. The synthon formation process between two similar functional groups like carboxylic acid functional groups of two molecules is known as homosynthon formation while the interaction between two different functional groups like carboxylic acid and amide functional group is called heterosynthon [11]. Here, in this study, $\Delta \mathrm{pKa}$ value method was utilized for prediction of $\mathrm{CC}$ formation, where difference between pKa value of acidic component (AN pKa 3.5) was subtracted from pKa value of less acidic or comparatively basic component (BZ pKa 4.2) and the $\triangle \mathrm{pKa}$ value obtained (0.7) between 0 to 1 , which is the most favourable range for $\mathrm{CC}$ formation [12]. CSD software was used to check the most prone functional group for synthon formation (Fig. 1). AN structure was analysed by using CSD code 'ACSA LA'. AN consists of centrosymmetric carboxylic acid dimer moieties $(\mathrm{O}-\mathrm{O})$ that are, in turn, linked via centro-symmetric methyl $\mathrm{C}-\mathrm{H}-\mathrm{O}(\mathrm{C}-\mathrm{O})$ contacts of acetyl groups, thereby forming $1 \mathrm{D}$ chains (Fig. 1a, b). The carboxylic acid functional group of AN was found to be the most favourable functional group on CSD analysis, while in case of BZ, only carboxylic acid is present, so it was hypothesized that homosynthon formation could take place between $\mathrm{COOH}$ functional of both components via hydrogen bonding.

\section{Analytical method development for the determination of AN}

\section{Determination of absorption maxima}

For the determination of absorption maxima $\left(\lambda_{\max }\right)$, UV spectrophotometric method was selected for the present work. Two hundred fifty milligrams of pure drug was dissolved in $1000 \mathrm{ml}$ 


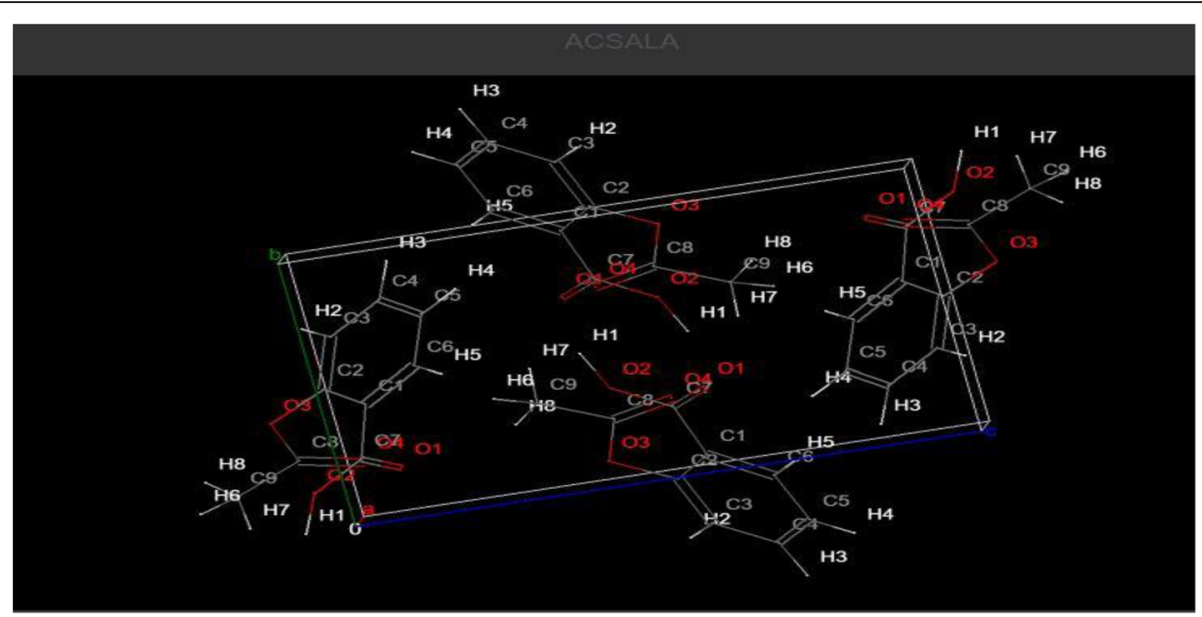

(a)

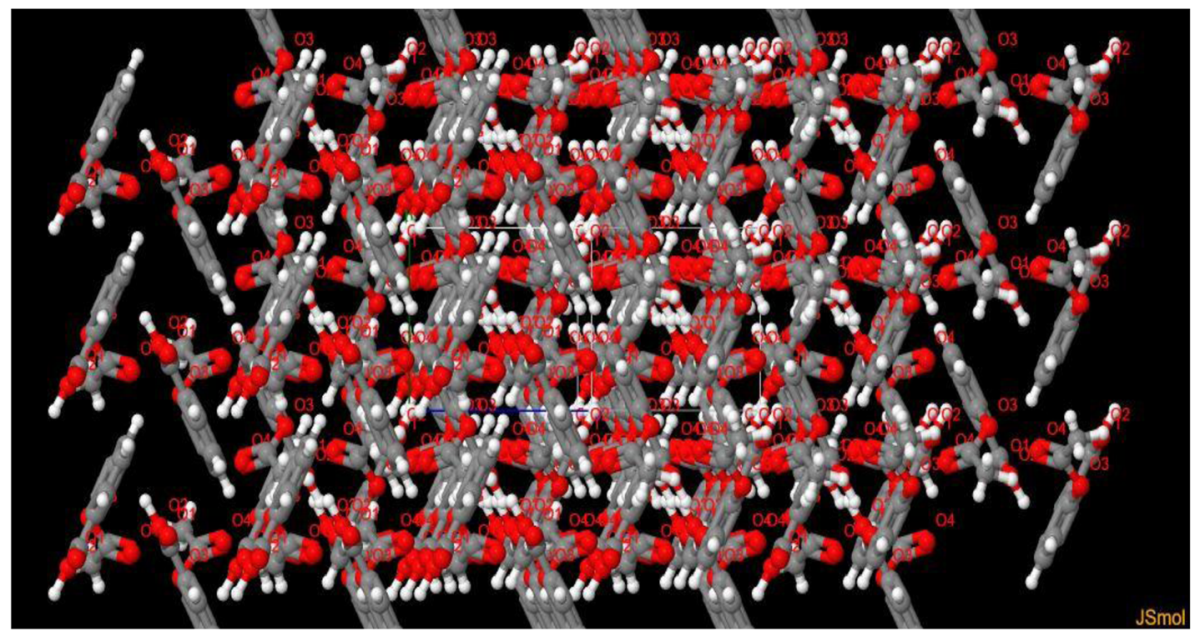

(b)

Fig. 1 Packing of AN molecules. a One-dimensional chains sustained by alternating carboxylic acid and acetyl group centrosymmetric dimers. $\mathbf{b}$ Acid dimers are connected via catemeric methyl $\mathrm{C}-\mathrm{H}-\mathrm{O}$ and phenyl $\mathrm{C}-\mathrm{H}-\mathrm{O}$ (not shown) hydrogen bonds

of $0.05 \mathrm{M}, 4.5 \mathrm{pH}$ sodium acetate buffer solution to prepare stock solution. $7.5 \mathrm{mcg} / \mathrm{ml}$ solution was scanned over between 200 and $400 \mathrm{~nm}$ using UV spectrophotometer (UV-1800, Shimadzu Corp., Japan) [13].

Table 1 Concentrations of samples for plotting calibration curve

\begin{tabular}{ll}
\hline $\begin{array}{l}\text { Amount of stock solution added } \\
\text { in } 100 \mathrm{ml} \text { of buffer solution }\end{array}$ & Concentration $(\mathrm{mcg} / \mathrm{ml})$ \\
\hline $1 \mathrm{ml}$ & 2.5 \\
$2 \mathrm{ml}$ & 5 \\
$3 \mathrm{ml}$ & 7.5 \\
$4 \mathrm{ml}$ & 10 \\
$5 \mathrm{ml}$ & 12.5 \\
$6 \mathrm{ml}$ & 15 \\
\hline
\end{tabular}

\section{Plotting the calibration curve}

The following concentrations were prepared by using stock solution. The various concentration of stock solution (Table 1) was diluted with $100 \mathrm{ml}$ of $0.05 \mathrm{M}$, $4.5 \mathrm{pH}$ sodium acetate buffer solution.

Table 2 In vivo anti-inflammatory study

\begin{tabular}{lllll}
\hline S. no. & Group $^{\text {a }}$ & Treatment & Dose & $\begin{array}{l}\text { Route of } \\
\text { administration }\end{array}$ \\
\hline 1. & I (control) & Carrageenan & $0.05 \mathrm{ml}$ of $1 \%$ sol. & $\begin{array}{l}\text { Injected in plantar } \\
\text { side of the left } \\
\text { hind paw }\end{array}$ \\
2. & II & AN & $100 \mathrm{mg} / \mathrm{kg}$ & Oral route \\
3. & III & AN: BZ CCs & $50 \mathrm{mg} / \mathrm{kg}$ & Oral route \\
4. & IV & AN: BZ CCs & $100 \mathrm{mg} / \mathrm{kg}$ & Oral route
\end{tabular}

${ }^{\mathrm{a}}$ Total number of rats $=24$ (six animals in each group) 
Table 3 Concentration vs absorbance data

\begin{tabular}{ll}
\hline Concentration $(\mathrm{mcg} / \mathrm{ml})$ & Absorbance \\
\hline 2.5 & 0.124 \\
5 & 0.237 \\
7.5 & 0.368 \\
10 & 0.479 \\
12.5 & 0.596 \\
15 & 0.713 \\
\hline
\end{tabular}

The samples taken were analysed by UV spectrophotometer (UV-1800, Shimadzu Corp., Japan) at $267 \mathrm{~nm}$ [13].

\section{Preparation of $A N: B Z C C S$}

On the basis of intense literature survey as well as concerned feasibility and practicability, the solvent evaporation method was selected for preparing the CCs [14]. AN and BZ were used as drug and coformer in equimolar amount in the fixed stoichiometric ratio respectively. $\mathrm{AN}$ (180 $\mathrm{mg}$ ) and $\mathrm{BZ}$ (244 $\mathrm{mg}$ ) were taken in the fixed stoichiometric ratio (1:2) and dissolved in ethanol. Sufficient amount of ethanol was used as a solvent for dissolving both components. The solvent was evaporated at room temperature, and after complete evaporation of the solvent, CCs were procured for further experimentations [15].

\section{Characterization of $A N, B Z$, their $P M$, and CCs}

For analytical purposes, AN, BZ, their PM and CCs were used. The PM of AN (100 mg) and BZ (100 mg) was prepared by mixing equal amount of both components respectively. No solvent was added in this PM.

\section{DSC analysis}

DSC analysis of AN, BZ, their PM and CCs was performed by using DSC Q10 V9.9 Build 303, US instrument. Two milligrams of the sample taken in a closed aluminium pan was heated from 20 to $160{ }^{\circ} \mathrm{C}$ in an atmosphere of nitrogen gas pursing at a flow of $60 \mathrm{ml} /$ min. An empty aluminium pan was taken as the reference pan.

\section{FT-IR analysis}

FT-IR study of AN, BZ, their PM and CCs was performed by employing $\mathrm{KBr}$ disc technique. The spectrum was recorded over the range of 4000-400 $\mathrm{cm}^{-1}$. The graph obtained was interpreted for the peaks obtained. The study was performed by using FT-IR Alpha Bruker 1206 0280, Germany instrument.

\section{XRD analysis}

XRD analysis of AN, BZ, their PM and CCs was performed by using the XRD model 'XPERT PRO' instrument with continuous scanning type at $2 \theta$ angle position.

\section{In vitro drug release study}

In vitro drug release was studied using USP type II dissolution apparatus (Lab India DS-8000) [13]. One hundred milligrams of drug was taken for dissolution studies [16]. The dissolution profile of equivalent amounts of CCs and marketed formulation was compared taking $0.05 \mathrm{M}, 4.5 \mathrm{pH}$ sodium acetate buffer solution $(500 \mathrm{ml})$ as the dissolution medium. USP type II dissolution apparatus was used for dissolution studies at paddle speed of $50 \mathrm{rpm}$ at $37 \pm$ $0.5{ }^{\circ} \mathrm{C}$ temperature for $90 \mathrm{~min}$. Five millilitres of samples was withdrawn at an interval of $15 \mathrm{~min}$

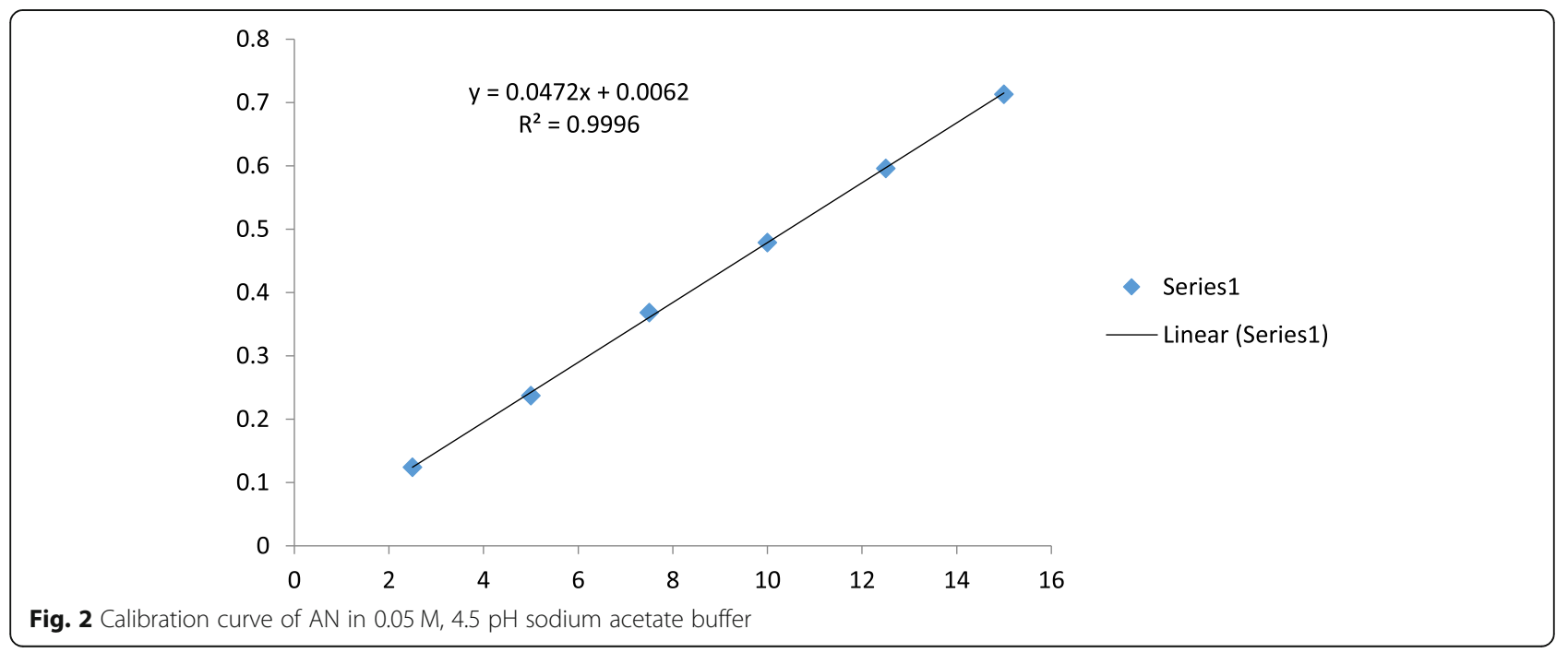




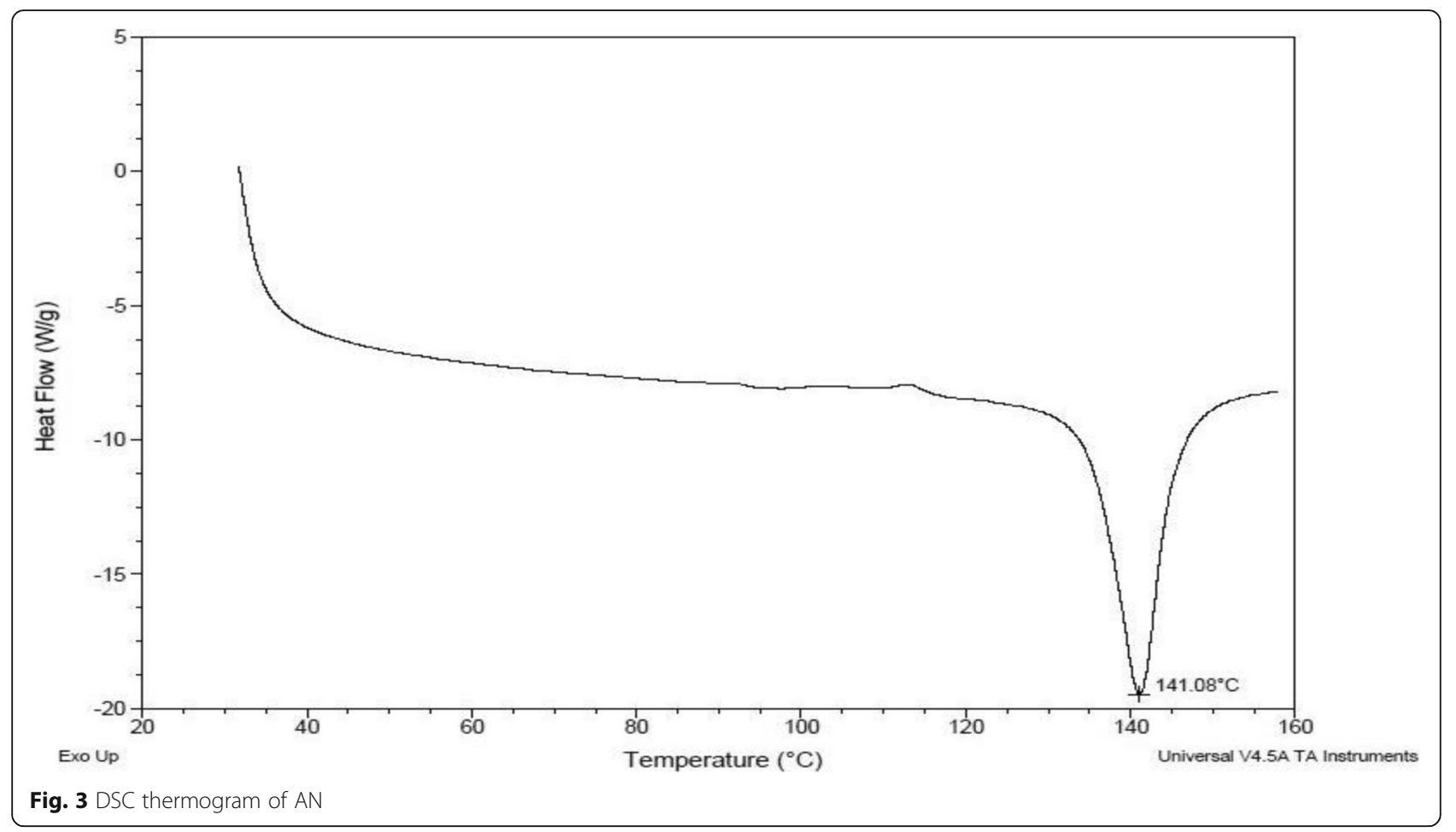

which was replaced simultaneously by an equivalent amount of dissolution medium. The samples were filtered through $0.45-\mu \mathrm{m}$ syringe filters and suitably diluted for spectrophotometric analysis. The samples taken were analysed by UV spectrophotometer (UV-1800, Shimadzu Corp., Japan) at $267 \mathrm{~nm}$ to calculate the amount of drug release [13].

\section{In vivo anti-inflammatory study \\ Carrageenan-induced paw edema}

In vivo studies were performed in the laboratory of the institution under prescribed conditions as per the IAEC guidelines and approval of the IAEC Committee. Animals were kept in air-conditioned housing facilities. Four transparent polycarbonate unbreakable

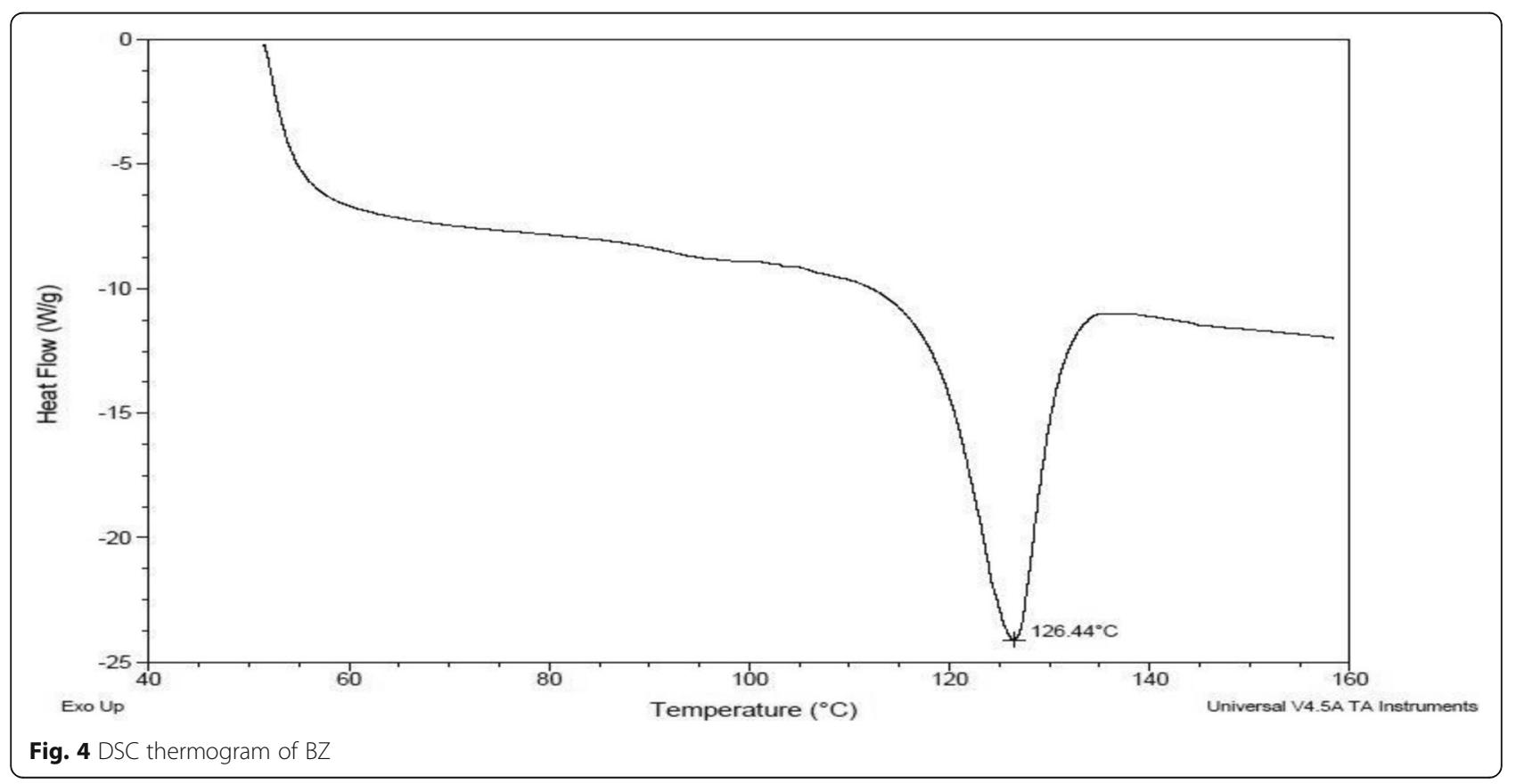




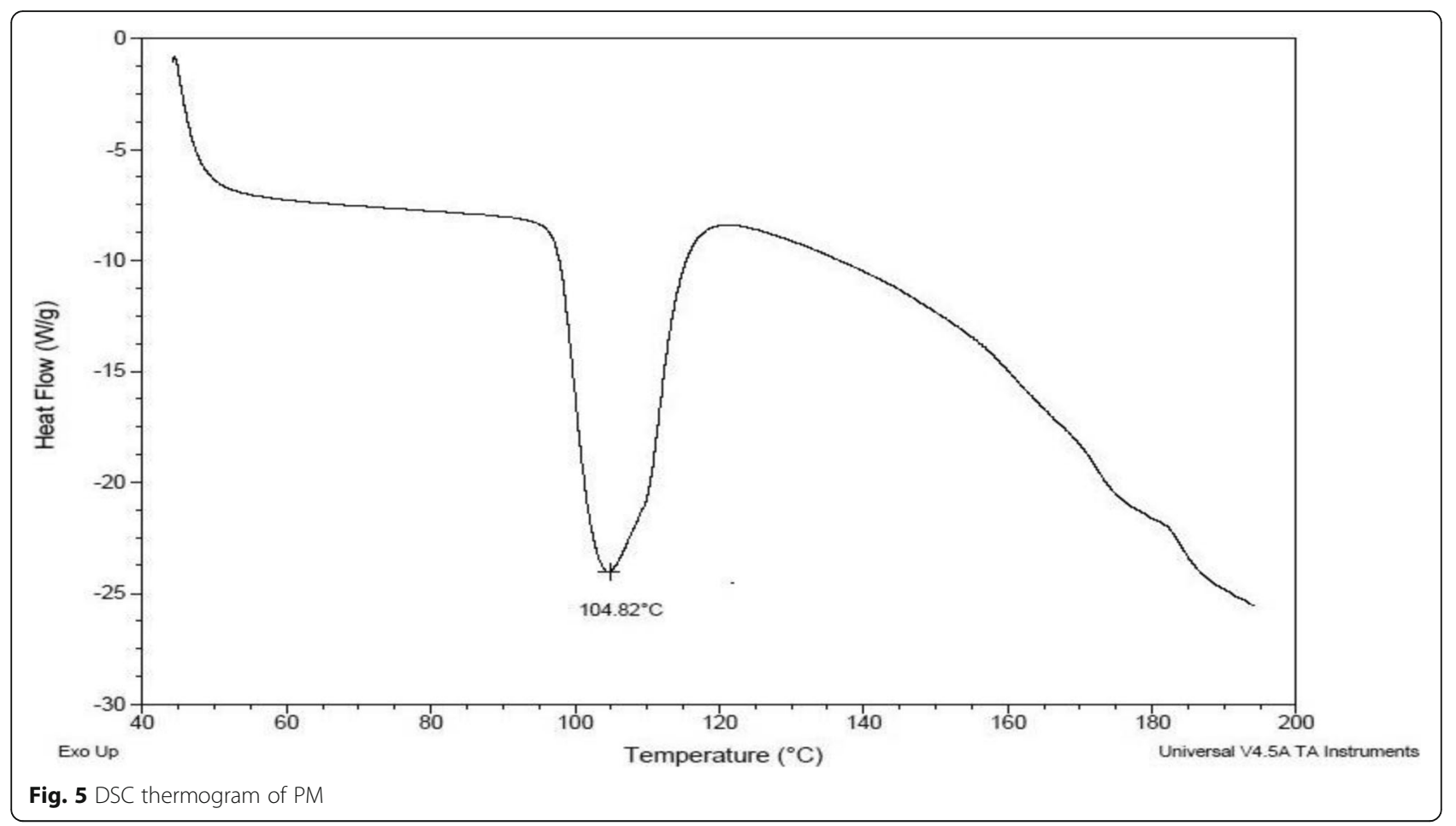

cages with corn bedding were used for storing the animals. Six animals in each cage were stored. They were treated with hygienic food and fresh water twice daily. The institute provided air-conditioned transportation facilities. For in vivo studies, AN pure drug was used as standard drug $(100 \mathrm{mg} / \mathrm{kg})$ while equivalent dose $(100 \mathrm{mg} / \mathrm{kg})$ and half dose $(50 \mathrm{mg} / \mathrm{kg})$ of CCs were used to evaluate the anti-inflammatory activity (Table 2). Half dose of CCs $(50 \mathrm{mg} / \mathrm{kg})$ was used because of improved dissolution profile of drug

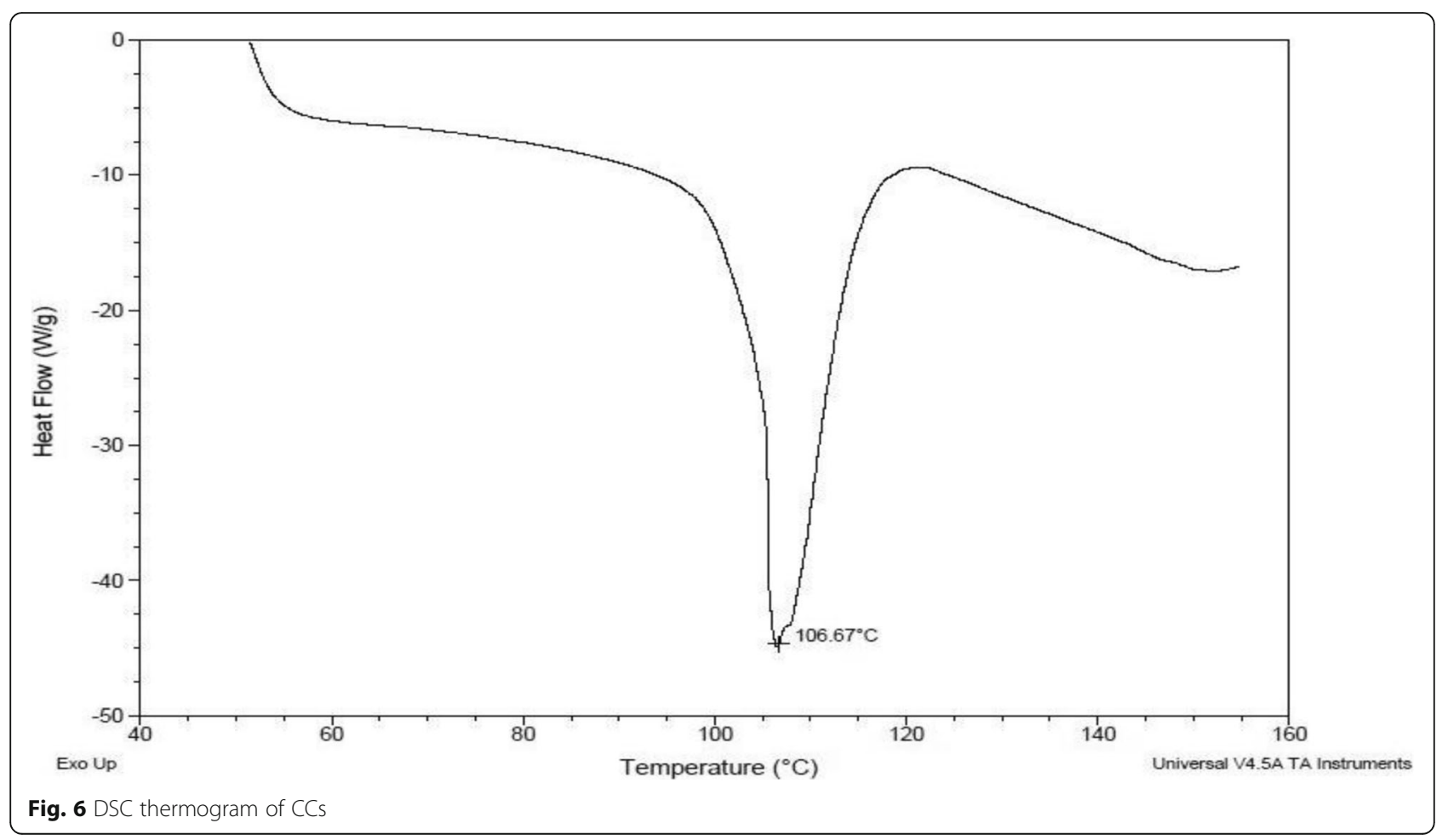




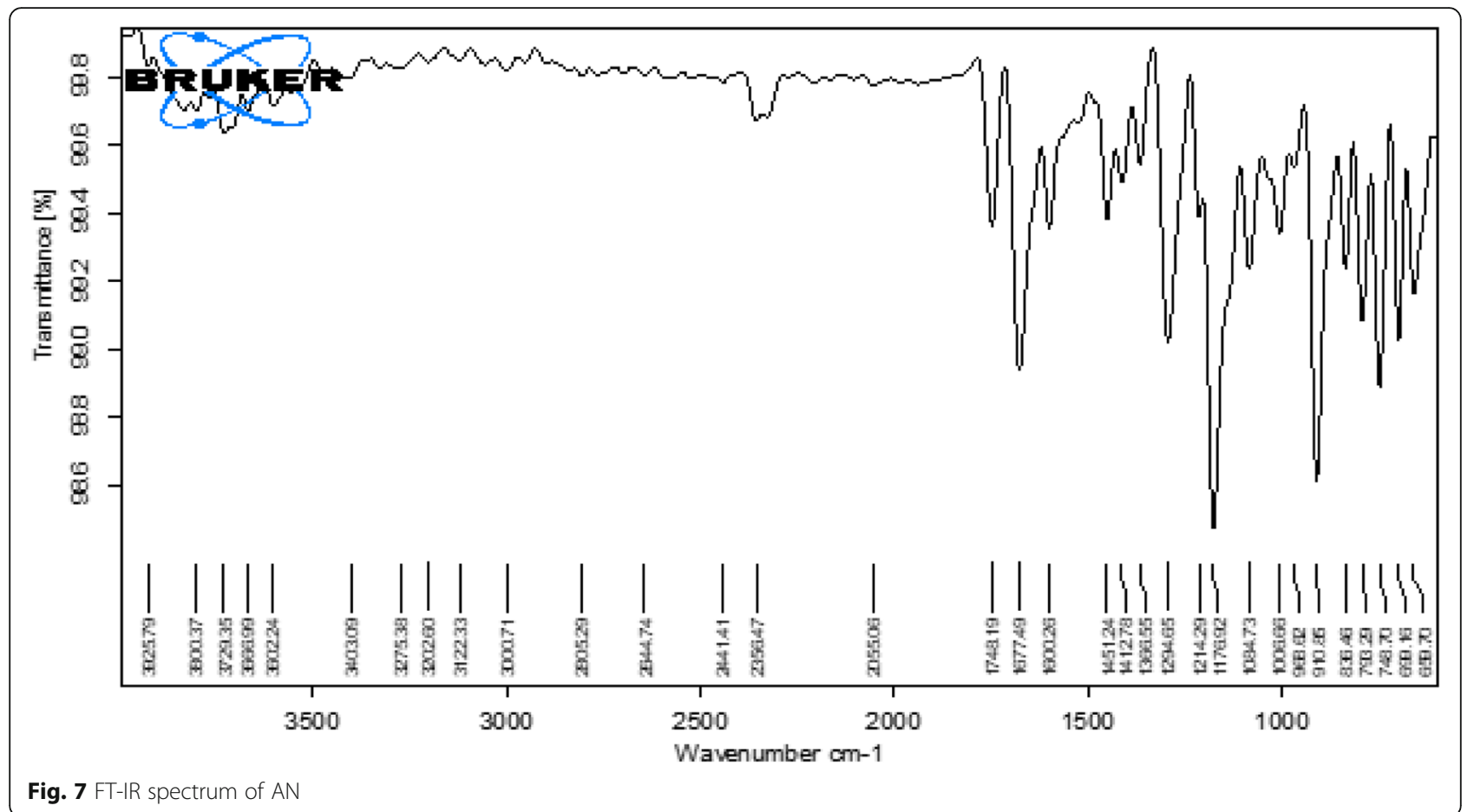

after cocrystallization. Wistar rats were starved overnight. To ensure uniform hydration, the rats received $5 \mathrm{ml}$ of water by stomach tube. After $30 \mathrm{~min}$, the rats were challenged by a subcutaneous injection of 0.05 $\mathrm{ml}$ of $1 \%$ solution of carrageenan into the planter side of the left hind paw. The paw was marked with ink at the level of the lateral malleolus and immersed in mercury up to this mark. The paw volume was measured plethysmographically after injection (of subcutaneous $0.05 \mathrm{ml}$ of $1 \%$ solution of carrageenan), at an interval of $1,2,3,4$ and $5 \mathrm{~h}$ after challenge $[17,18]$. Anaesthetic agents were not used since the procedures were not associated with routine blood withdrawal.

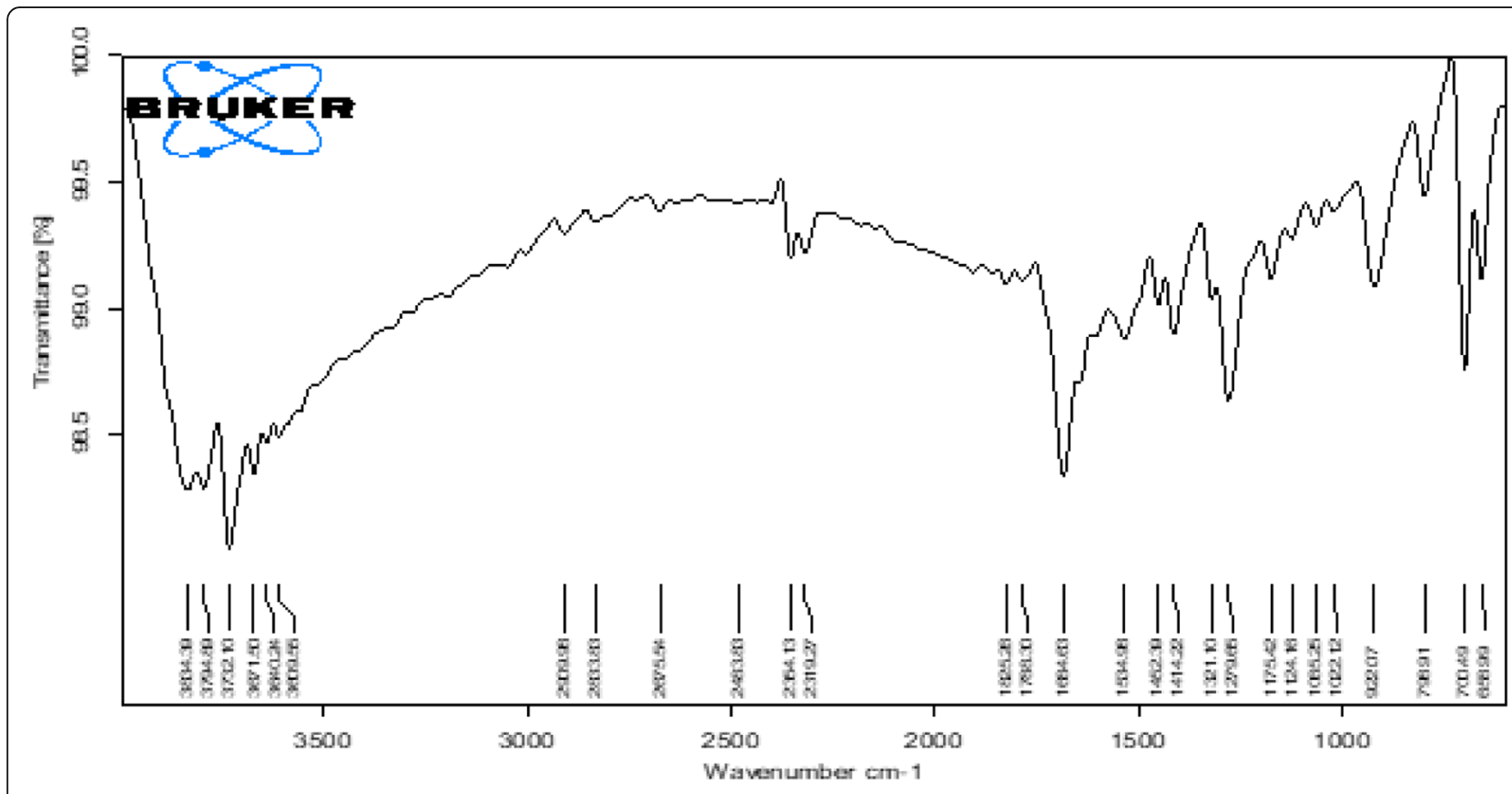

Fig. 8 FT-IR spectrum of BZ 


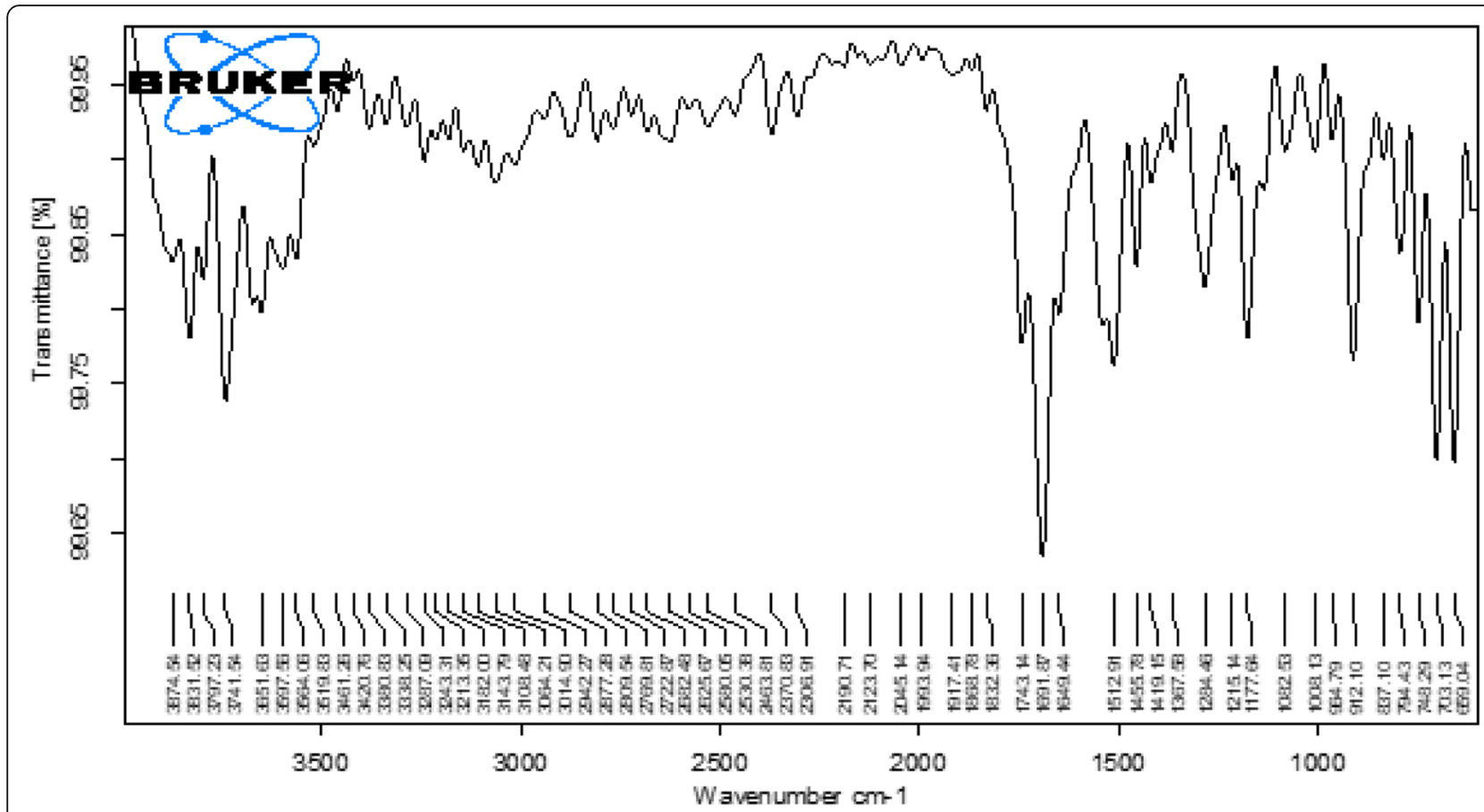

Fig. 9 FT-IR spectrum of PM

\section{Result}

\section{Determination of absorption maxima}

$7.5 \mathrm{mcg} / \mathrm{ml}$ solution was scanned over between 400 and $200 \mathrm{~nm}$ using UV spectrophotometer (UV-1800, Shimadzu Corp., Japan). The absorption maxima $\left(\lambda_{\max }\right)$ was obtained at $267 \mathrm{~nm}$ [13].

\section{Establishment of calibration curve}

Various concentrations of AN in $0.05 \mathrm{M}, 4.5 \mathrm{pH}$ sodium acetate buffer were taken (Table 3). Absorbance of each concentration was determined at $\lambda_{\max } 267.40 \mathrm{~nm}$. The graph was plotted between absorbance and concentrations (Fig. 2). $R^{2}$ value was calculated on the basis of calibration curve, and it was found to be $0.9996 . R^{2}$ is a statistical measure of fit that indicates how much variation of a dependent variable is explained by the independent variable(s) in a regression model.

\section{Characterization of AN, BZ, their PM and CCs DSC analysis}

DSC analysis was performed by using DSC Q10 V9.9 Build 303, US instrument. The DSC thermogram of AN (Fig. 3) shows a sharp endothermic peak representing its melting point at $141.08{ }^{\circ} \mathrm{C}$. The DSC thermogram of BZ (Fig. 4) shows a sharp endothermic peak representing its melting point at $126.44{ }^{\circ} \mathrm{C}$. No other peak appeared in both thermograms which shows that the samples procured were pure. In the thermogram of PM (Fig. 5), the corresponding peaks of $\mathrm{AN}$ and $\mathrm{BZ}$ are absent; instead, a sharp peak at $106.67{ }^{\circ} \mathrm{C}$ shows the physicochemical interaction of AN with BZ. The DSC thermogram of CCs (Fig. 6) shows a sharp endothermic peak at $106.67{ }^{\circ} \mathrm{C}$. No other peak appeared in this thermogram which shows that the drug has been completely cocrystallized.

Table 4 FT-IR data of AN, BZ, their PM and CCs

\begin{tabular}{lllll}
\hline Functional group & AN & BZ & PM & CCS \\
\hline C-O stretch & $1176-1214$ (acidic) & $1175-1279$ (acidic) & $1177-1294$ (acidic) & 1067 (alcohol) \\
-C-H bending & $1366-1451$ (alkane) & - & - & $1386-1450$ (alkane) \\
C=O stretch & - & 1684 (carbonyl) & $1649-1743$ (carbonyl) & 1624 (carbonyl) \\
O-H stretch & - & $3609-3794\{$ alcohol (non-bonded)\} & $3461-3797\{$ alcohol (non-bonded)\} & 3405 \{alcohol (bonded)\} \\
C=C stretch & $1600-1748$ (carbonyl) & - & - & - \\
\hline
\end{tabular}




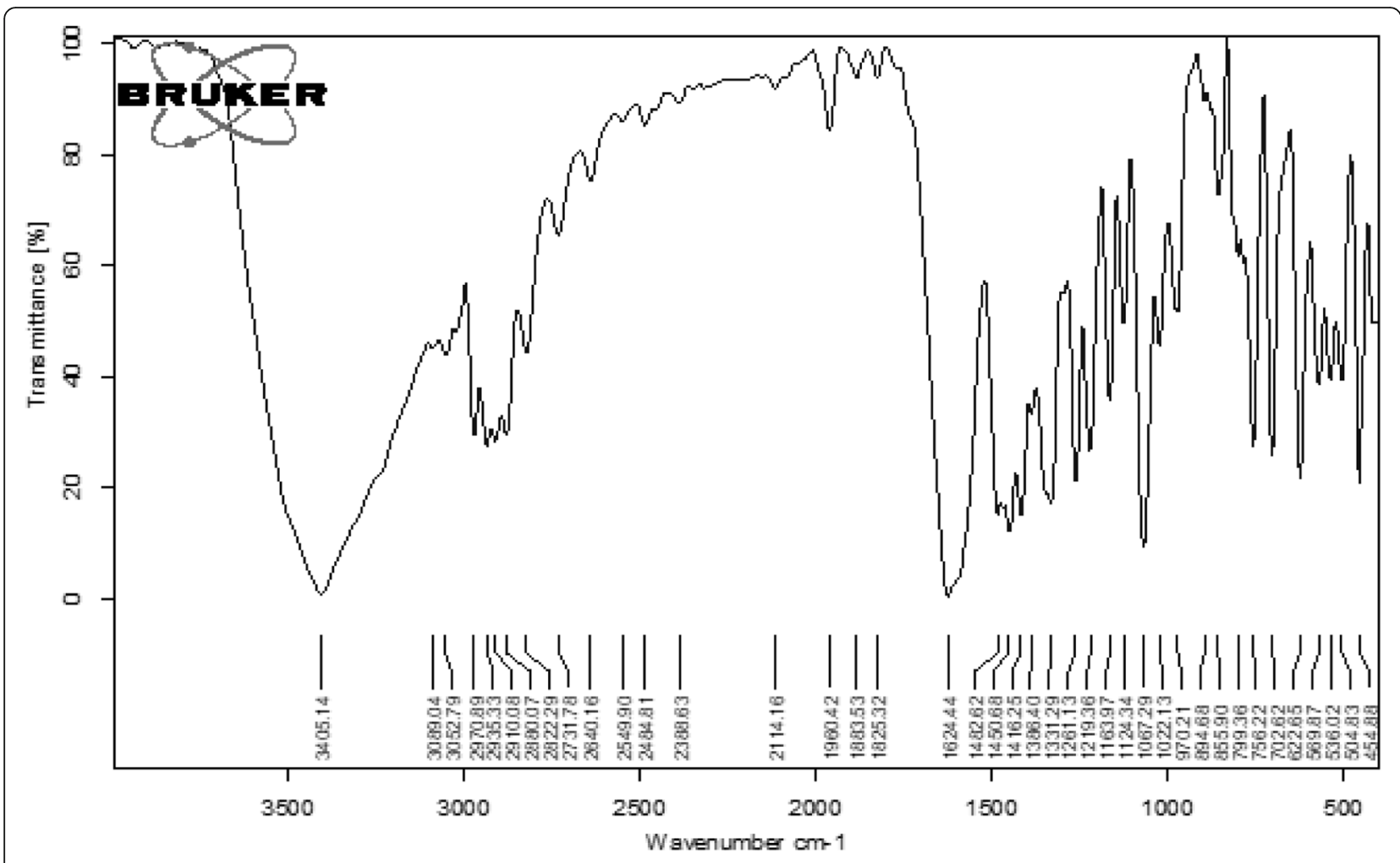

Fig. 10 FT-IR spectra of CCS

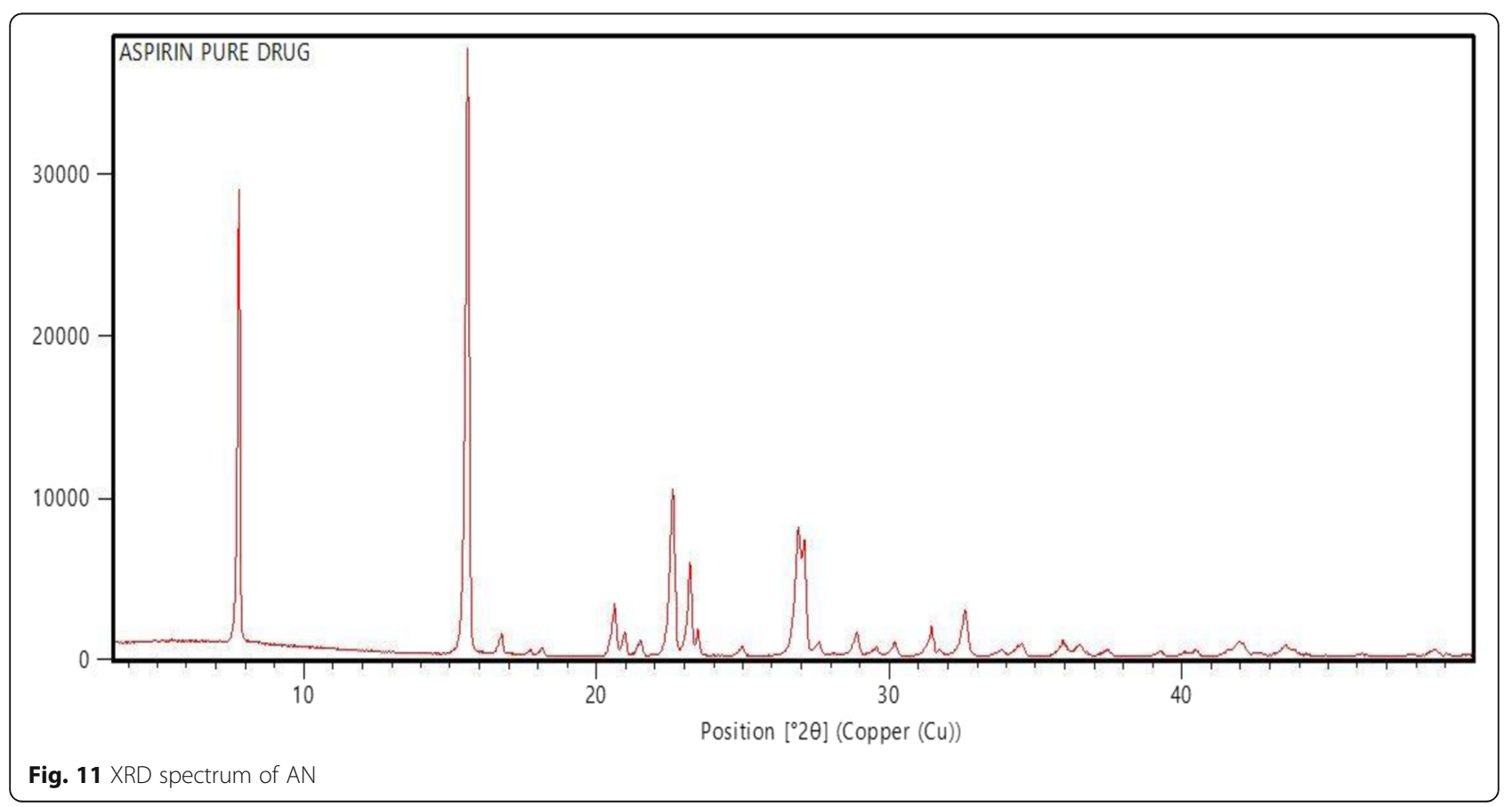


Table 5 XRD Data of AN, BZ, their PM and CCs

\begin{tabular}{|c|c|c|c|c|}
\hline Pos. $\left[{ }^{\circ} 2 \theta\right]$ & FWHM total $\left[^{\circ} 2 \theta\right]$ & d-spacing $[\AA]$ & Rel. int. [\%] & Area $\left[\right.$ cts $^{* 0} 2 \theta$ ] \\
\hline \multicolumn{5}{|l|}{ AN } \\
\hline 7.7701 & 0.0912 & 11.36892 & 77.66 & 2228.16 \\
\hline 15.5695 & 0.1450 & 5.68690 & 100.00 & 4056.83 \\
\hline 16.7211 & 0.1610 & 5.29772 & 3.37 & 167.37 \\
\hline 20.5856 & 0.1995 & 4.31109 & 8.13 & 464.94 \\
\hline 22.5687 & 0.1776 & 3.93656 & 28.63 & 1584.68 \\
\hline 23.1687 & 0.1197 & 3.83595 & 17.60 & 838.48 \\
\hline 23.4501 & 0.0738 & 3.79055 & 4.68 & 88.28 \\
\hline 26.8909 & 0.2891 & 3.31283 & 22.35 & 2179.81 \\
\hline \multicolumn{5}{|l|}{ BZ } \\
\hline 7.9682 & 0.1546 & 11.08670 & 72.62 & 712.10 \\
\hline 8.1026 & 0.1439 & 10.90312 & 85.34 & 924.48 \\
\hline 16.1232 & 0.2723 & 5.49282 & 62.71 & 1029.17 \\
\hline 17.0640 & 0.1480 & 5.19203 & 61.59 & 691.46 \\
\hline 17.1394 & 0.0789 & 5.16936 & 100.00 & 685.06 \\
\hline 18.8945 & 0.3026 & 4.69296 & 8.42 & 145.97 \\
\hline 21.0225 & 0.0892 & 4.22247 & 8.87 & 71.29 \\
\hline \multicolumn{5}{|c|}{ AN to BZ PM (1:1) } \\
\hline 7.8562 & 0.0795 & 11.24444 & 19.74 & 2005.94 \\
\hline 8.1908 & 0.1036 & 10.78594 & 100.00 & $10,521.72$ \\
\hline 15.6594 & 0.1318 & 5.65445 & 26.34 & 3504.45 \\
\hline 16.3305 & 0.1194 & 5.42355 & 39.16 & 4689.20 \\
\hline 16.8154 & 0.1291 & 5.26821 & 0.82 & 137.65 \\
\hline 17.2844 & 0.0837 & 5.12631 & 8.02 & 798.11 \\
\hline 17.7801 & 0.1798 & 4.98450 & 0.18 & 28.84 \\
\hline 18.1978 & 0.1678 & 4.87101 & 0.25 & 56.54 \\
\hline \multicolumn{5}{|c|}{$A N$ to $B Z C C s$} \\
\hline 5.1023 & 0.1283 & 14.47183 & 66.48 & 707.89 \\
\hline 6.4690 & 1.3361 & 9.74326 & 5.67 & 250.19 \\
\hline 7.6130 & 0.1444 & 11.30652 & 33.70 & 1273.85 \\
\hline 9.5991 & 0.1417 & 10.82663 & 15.49 & 1556.17 \\
\hline 11.4826 & 0.1138 & 7.83616 & 34.12 & 127.16 \\
\hline 12.8963 & 0.1239 & 10.90924 & 96.28 & 3824.37 \\
\hline 14.4608 & 0.5332 & 6.38386 & 29.54 & 79.94 \\
\hline 15.2950 & 0.1800 & 5.67762 & 24.22 & 1446.88 \\
\hline 16.2736 & 0.1760 & 5.44237 & 20.24 & 1267.30 \\
\hline 17.1773 & 0.1288 & 5.15803 & 0.49 & 2877.58 \\
\hline 19.2767 & 1.0006 & 5.12857 & 0.63 & 402.56 \\
\hline 19.9027 & 0.1189 & 5.12821 & 100.00 & 7890.53 \\
\hline 20.6179 & 0.2173 & 4.30441 & 1.17 & 225.30 \\
\hline 21.0057 & 0.1905 & 4.22581 & 0.53 & 64.39 \\
\hline
\end{tabular}

FT-IR analysis

The characteristic peaks of AN (Fig. 7), BZ (Fig. 8), their PM (Fig. 9) and CCs are explained in (Table 4) respectively. The characterstic peaks present in FT-IR spectra of AN and BZ, viz. C=C stretch $1600-1748$ and 1684 for carbonyl functional group and $\mathrm{C}-\mathrm{O}$ stretch 
1176-1214 and 1175-1279 for carboxylic acid functional group respectively, are also present in their PM (Fig. 9) with minor peak shifting due to some weak Van der Waals forces [19]. This conformed that without addition of solvent in the mixture of drug and coformer, they did not interact chemically with each other. After addition of ethanol in the mixture of AN and $\mathrm{BZ}$ in the stoichiometric ratio of $1: 2$, homosynthon formation occurred due to possible hydrogen bonding between the $\mathrm{COOH}$ group present in both drug and coformer, which was evident through the corresponding FT-IR spectra (Fig. 10) of CCs.

\section{XRD analysis}

The XRD spectrum of AN (Fig. 11) showed major characteristic peaks on $2 \theta$ angle position at 7.7701, 15.5695, 22.5687 and 26.8909 with relative intensity (in percentage) of 77.66, 100.00, 28.63 and 22.35 respectively (Table 5). The XRD spectrum of BZ (Fig. 12) showed major characteristic peaks on $2 \theta$ angle position at 7.9682, 8.1026, 16.1232 and 17.1394 with relative intensity (in percentage) of 72.62, 85.34, 62.71 and 100.00 respectively (Table 5). The XRD spectrum of PM (Fig. 13) of AN and BZ showed major characteristic peaks on $2 \theta$ angle position at 8.1908 , 15.6594 and 16.3305 with relative intensity (in percentage) of 100.00, 26.34 and 39.16 respectively (Table 5). The relative intensities of peaks revealed the purity of drug and coformer samples. The XRD spectrum of CCs (Fig. 14) showed major characteristic peaks on $2 \theta$ angle position at 5.1023, 7.6130, 11.4826, 12.8963 and 19.9027 with relative intensity (in percentage) of 66.48, 33.70, 34.12, 96.28 and 100.00 respectively (Table 5).

\section{In vitro drug release study}

The in vitro drug release of AN, marketed formulation and CCs in $0.05 \mathrm{M}, 4.5 \mathrm{pH}$ sodium acetate buffer solution $(500 \mathrm{ml})$ are presented in Fig. 15. The pure drug exhibited approx. $31 \%$ drug solubility over a 90 min period while marketed formulation and CCs exhibited $60 \%$ and $87 \%$ drug release respectively (Fig. 16) (Table 6).

\section{In vivo anti-inflammatory study}

The anti-inflammatory effects of CCs on carrageenaninduced edema in rat's hind paws are presented in Fig. 17. The dose of CCs in group III was kept half compared to the standard drug AN, and in group IV, equivalent dose of CCs to the standard drug was used (Table 2). There was no reduction in inflammation found in case of group I or control group rats treated with saline. The results showed that CCs significantly reduced the inflammation in $100 \mathrm{mg} / \mathrm{kg}$ dose followed by standard anti-inflammatory drug, AN $100 \mathrm{mg} / \mathrm{kg}$. The values of reduction in paw volume in each group, $0.99 \pm 0.03,0.78 \pm 0.04,0.81 \pm 0.009$ and 0.63 \pm 0.01 , were found respectively at $5 \mathrm{~h}$ after carrageenan administration (Table 7 ).

\section{Discussion}

The cocrystallization process basically depends upon synthon formation between two molecules. For analysis of synthon formation, there is a need to study different functional groups in molecules prone to make synthons with each other. There are numerous techniques to detect these functional groups like CSD and COSMOS-RS

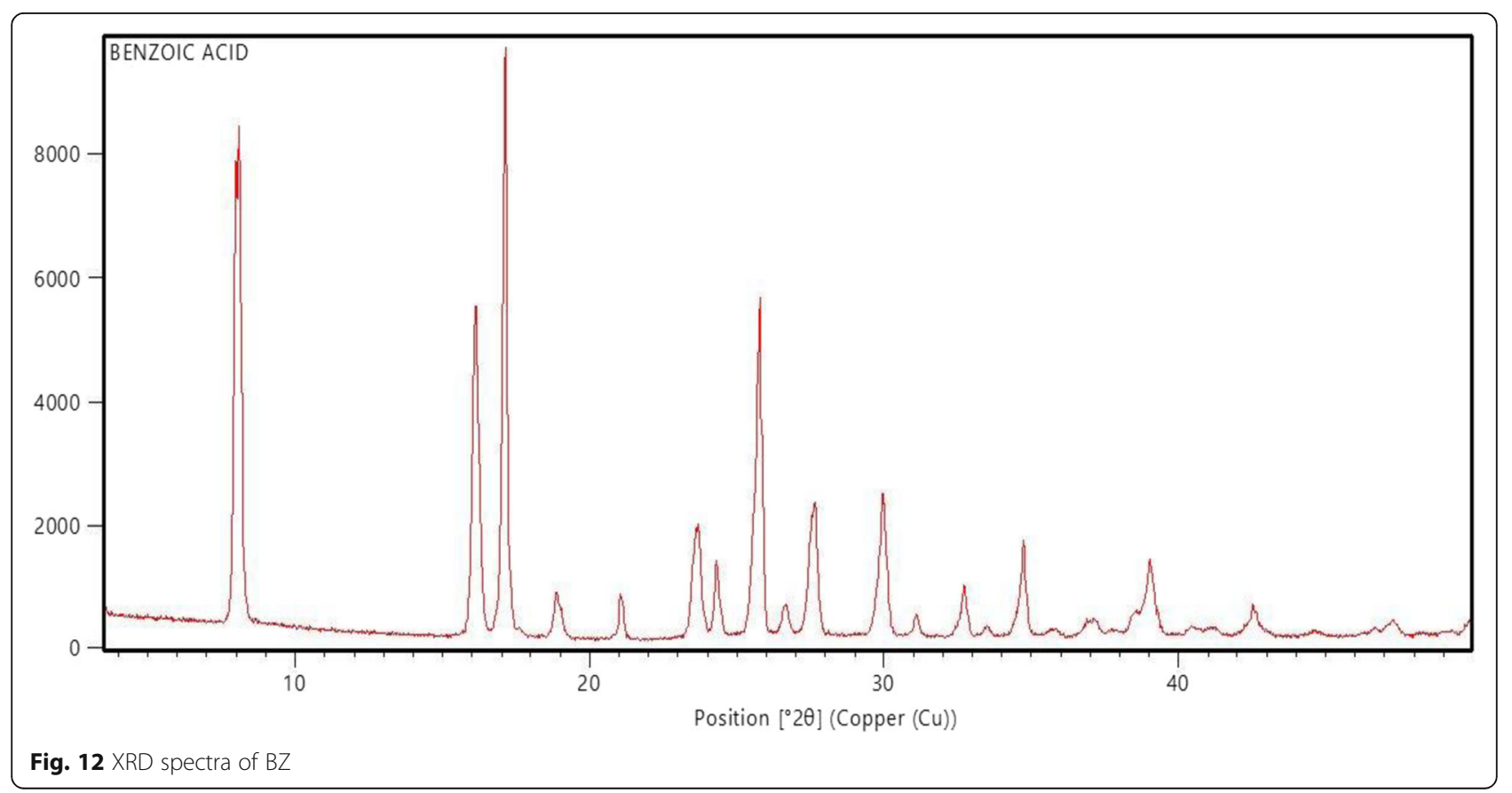




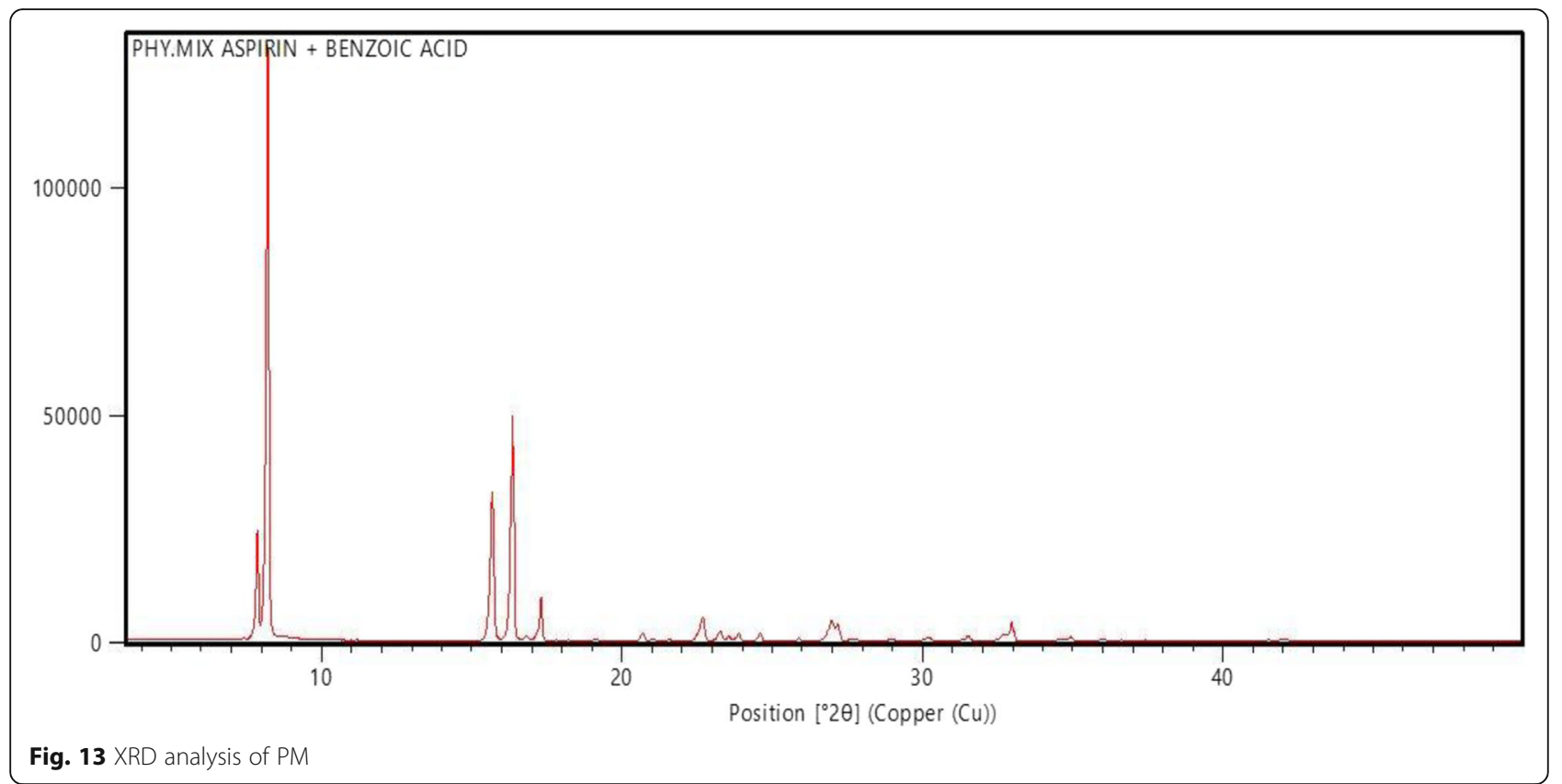

techniques. Another method used for prediction of cocrystal formation is $\Delta \mathrm{pKa}$ value method [10]. Here, in this study, we used CSD and $\triangle \mathrm{pKa}$ value method to select the API and coformer. In the DSC study, different sharp peaks were obtained at $141.08{ }^{\circ} \mathrm{C}, 126.44{ }^{\circ} \mathrm{C}$ and $104.82{ }^{\circ} \mathrm{C}$ in the thermogram of AN (Fig. 3), BZ (Fig. 4) and PM (Fig. 5) respectively. In the thermogram of the CCs (Fig. 6) and PM of AN and BZ, the corresponding peaks of AN and BZ are absent, instead of a sharp peak at $106.67{ }^{\circ} \mathrm{C}$ and $104.82{ }^{\circ} \mathrm{C}$ respectively, which shows that the drug has been cocrystallized with coformer when the temperature of their PM in the DSC pans was increased. In the FT-IR study, the characterstic peaks in FT-IR spectra of AN and BZ, viz. C=C stretch 16001748 and 1684 for carbonyl functional group and $\mathrm{C}-\mathrm{O}$ stretch 1176-1214 and 1175-1279 for carboxylic acid

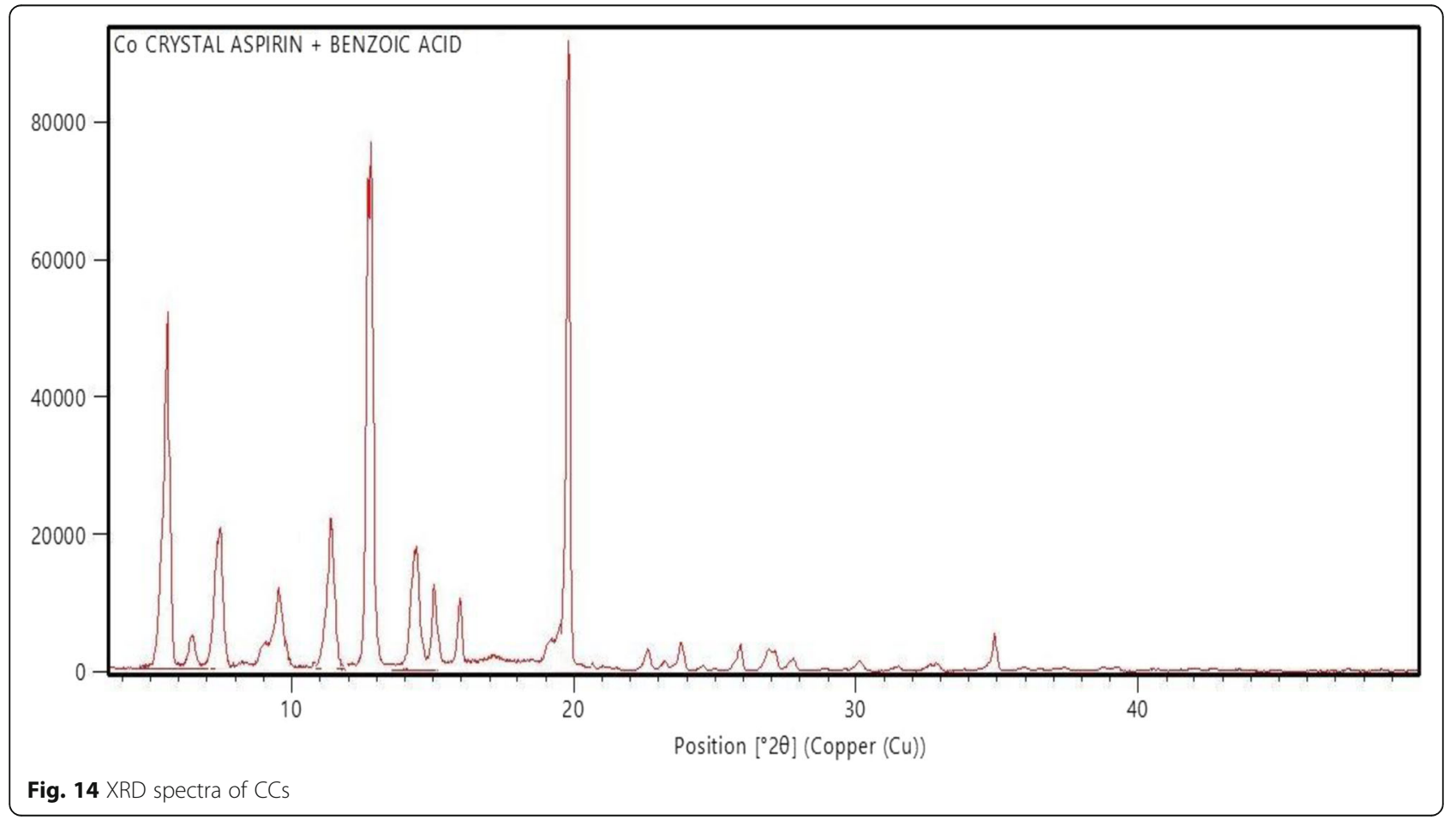




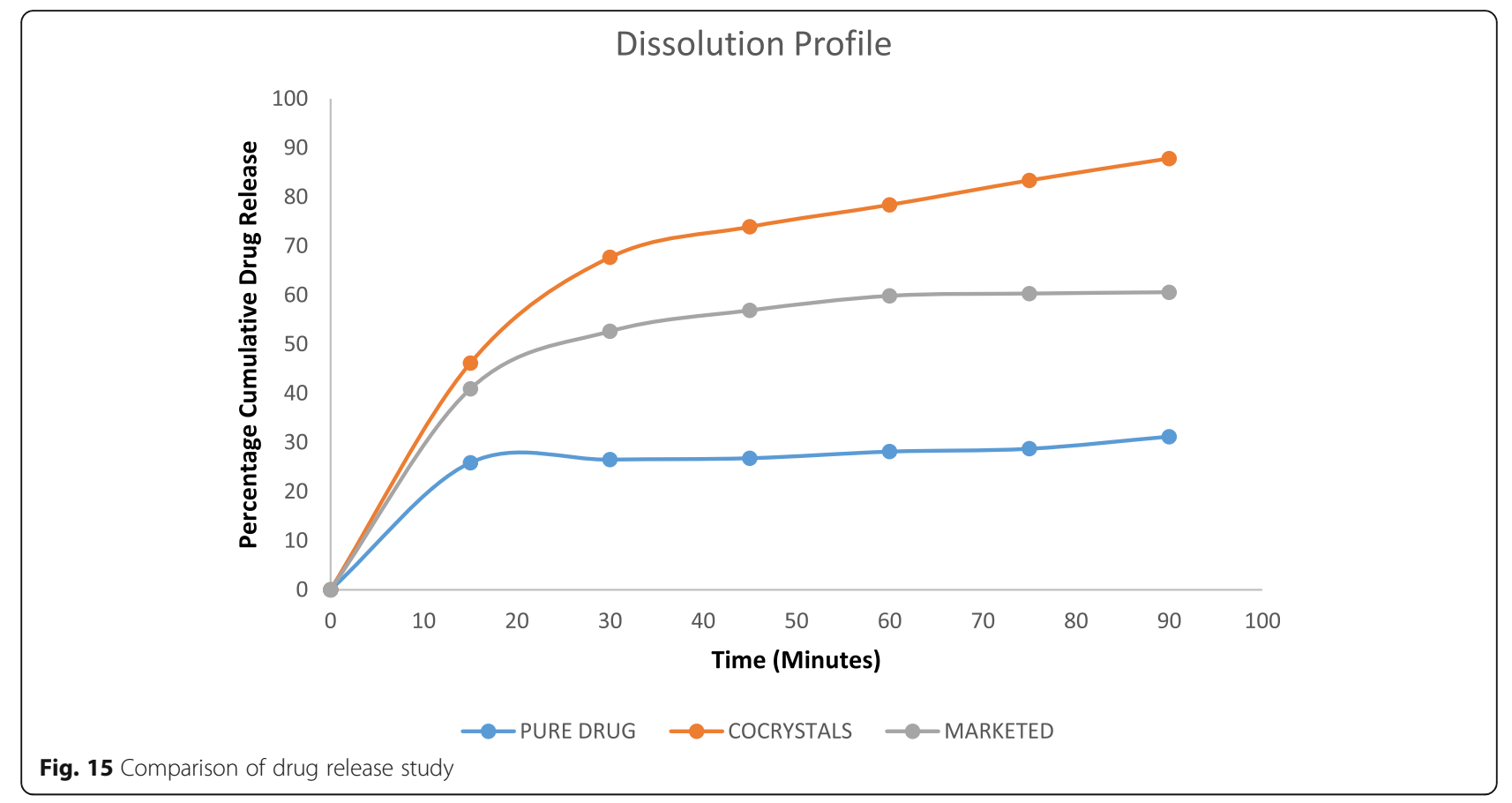

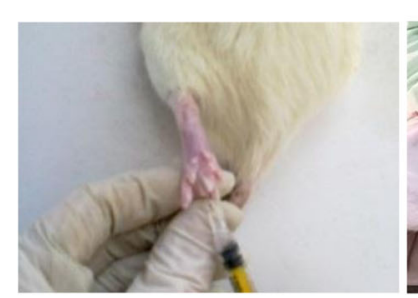

(a)

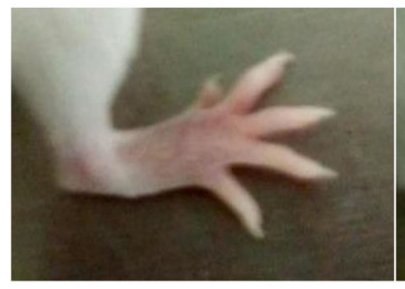

(d)

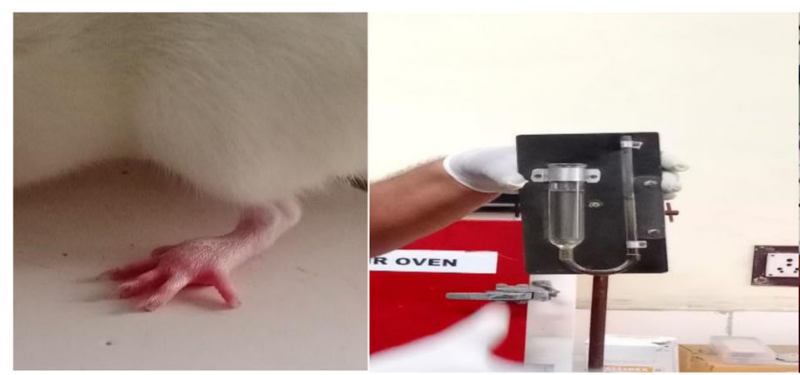

(g)

(b)

(h)

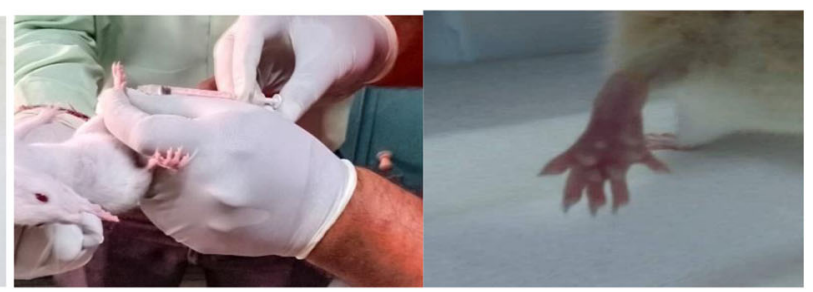

(c)

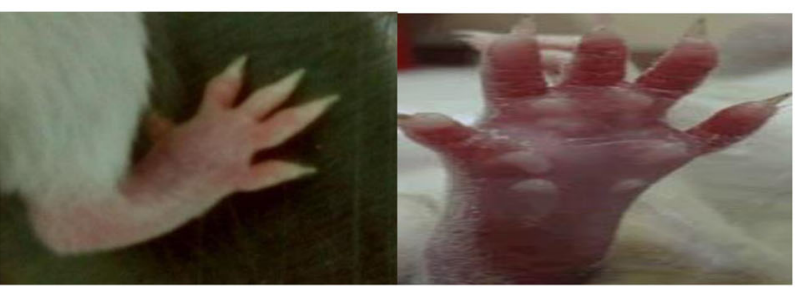

(f)

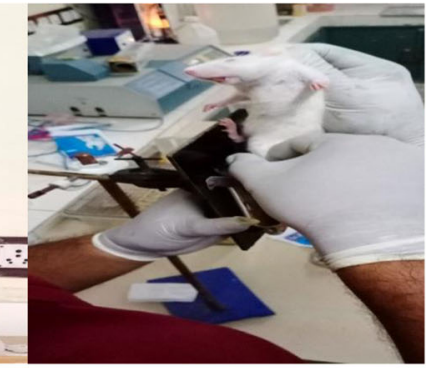

(i)

Fig. $\mathbf{1 6}$ a, $\mathbf{b}$ Injection of $0.05 \mathrm{ml}$ of $1 \%$ solution of carrageenan into the plantar side of the left hind paw. $\mathbf{c}-\mathbf{g}$ Inflammation in rat paw after carrageenan injection. $\mathbf{h}$ Establishment of plethysmometer assembly. i Measurement of inflammation by using plethysmometer assembly 
Table 6 Drug release study data

\begin{tabular}{|c|c|c|c|c|c|c|c|c|}
\hline Drug abs & Conc (mcg/ml) & $\begin{array}{l}\text { Dilution } \\
\text { factor }\end{array}$ & $\begin{array}{l}\text { Actual drug conc } \\
\text { in } 1 \mathrm{ml}(\mathrm{mcg} / \mathrm{ml})\end{array}$ & $\begin{array}{l}\text { Drug in } 5 \mathrm{ml} \\
(\mathrm{mcg} / \mathrm{ml})\end{array}$ & $\begin{array}{l}\text { Total drug } \\
\text { (mcg/ml) }\end{array}$ & $\begin{array}{l}\text { Total cumulative } \\
\text { drug release }\end{array}$ & Drug in mg & $\begin{array}{l}\% \text { cumulative } \\
\text { drug release }\end{array}$ \\
\hline \multicolumn{9}{|l|}{ AN } \\
\hline 0.369 & 7.686440678 & 20 & 153.7288136 & 768.6440678 & $76,864.40678$ & $76,864.40678$ & 76.86440678 & 25.62146893 \\
\hline 0.378 & 7.877118644 & 20 & 157.5423729 & 787.7118644 & $78,771.18644$ & $79,539.83051$ & 79.53983051 & 26.51327684 \\
\hline 0.382 & 7.961864407 & 20 & 159.2372881 & 796.1864407 & $79,618.64407$ & $80,406.35593$ & 80.40635593 & 26.80211864 \\
\hline 0.401 & 8.36440678 & 20 & 167.2881356 & 836.440678 & $83,644.0678$ & $84,440.25424$ & 84.44025424 & 28.14675141 \\
\hline 0.409 & 8.533898305 & 20 & 170.6779661 & 853.3898305 & $85,338.98305$ & $86,175.42373$ & 86.17542373 & 28.72514124 \\
\hline 0.444 & 9.275423729 & 20 & 185.5084746 & 927.5423729 & $92,754.23729$ & $93,607.62712$ & 93.60762712 & 31.20254237 \\
\hline \multicolumn{9}{|l|}{ CCs } \\
\hline 0.529 & 11.07627119 & 25 & 276.9067797 & 1384.533898 & $13,8453.3898$ & $138,453.3898$ & 138.4533898 & 46.15112994 \\
\hline 0.768 & 16.13983051 & 25 & 403.4957627 & 2017.478814 & $20,1747.8814$ & $203,132.4153$ & 203.1324153 & 67.71080508 \\
\hline 0.836 & 17.58050847 & 25 & 439.5127119 & 2197.563559 & $21,9756.3559$ & $221,773.8347$ & 221.7738347 & 73.92461158 \\
\hline 0.886 & 18.63983051 & 25 & 465.9957627 & 2329.978814 & $23,2997.8814$ & $235,195.4449$ & 235.1954449 & 78.39848164 \\
\hline 0.942 & 19.82627119 & 25 & 495.6567797 & 2478.283898 & $24,7828.3898$ & $250,158.3686$ & 250.1583686 & 83.38612288 \\
\hline 0.992 & 20.88559322 & 25 & 522.1398305 & 2610.699153 & $26,1069.9153$ & $263,548.1992$ & 263.5481992 & 87.84939972 \\
\hline \multicolumn{9}{|c|}{ Marketed formulation } \\
\hline 0.465 & 9.720338983 & 25 & 243.0084746 & 1215.042373 & $12,1504.2373$ & $122,719.2797$ & 122.7192797 & 40.90642655 \\
\hline 0.598 & 12.53813559 & 25 & 313.4533898 & 1567.266949 & $15,6726.6949$ & $157,941.7373$ & 157.9417373 & 52.64724576 \\
\hline 0.645 & 13.53389831 & 25 & 338.3474576 & 1691.737288 & $16,9173.7288$ & $170,740.9958$ & 170.7409958 & 56.91366525 \\
\hline 0.678 & 14.23305085 & 25 & 355.8262712 & 1779.131356 & $17,7913.1356$ & $179,604.8729$ & 179.6048729 & 59.86829096 \\
\hline 0.683 & 14.33898305 & 25 & 358.4745763 & 1792.372881 & $17,9237.2881$ & $181,016.4195$ & 181.0164195 & 60.3388065 \\
\hline 0.686 & 14.40254237 & 25 & 360.0635593 & 1800.317797 & $18,0031.7797$ & $181,824.1525$ & 181.8241525 & 60.60805085 \\
\hline
\end{tabular}

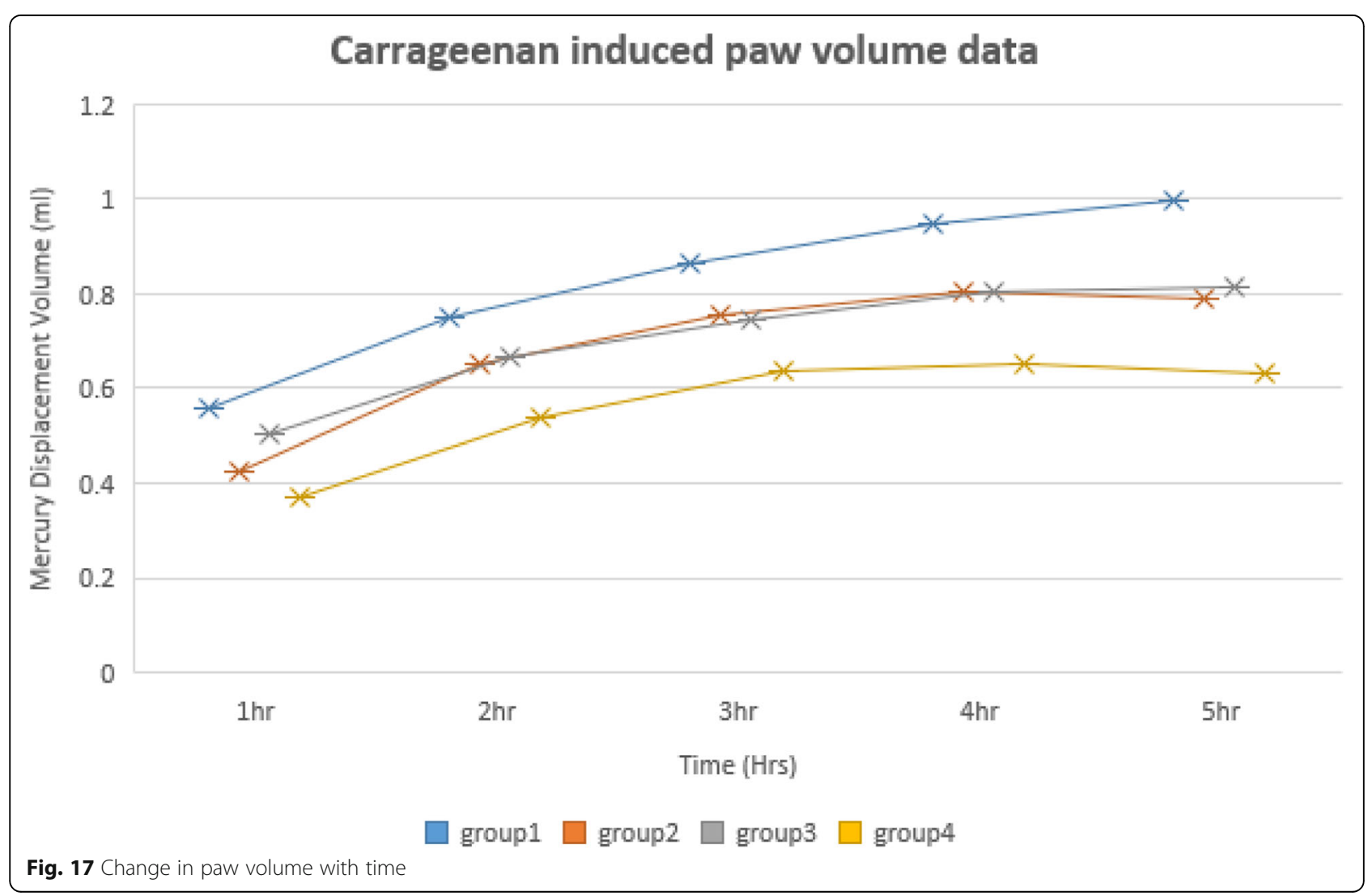


Table 7 Carrageenan-induced paw volume data

\begin{tabular}{lllll}
\hline Time & $\begin{array}{l}\text { Group1 }^{\mathbf{a}} \\
\text { Control group }\end{array}$ & $\begin{array}{l}\text { Group2 }^{\mathbf{a}} \\
\text { AN }(100 \mathrm{mg} / \mathrm{kg})\end{array}$ & $\begin{array}{l}\text { Group3 }^{\mathbf{a}} \\
\text { AN:BZ CCs }(50 \mathrm{mg} / \mathrm{kg})\end{array}$ & $\begin{array}{l}\text { Group4 }^{\mathbf{a}} \\
\text { AN:BZ CCs (100 mg/kg) }\end{array}$ \\
\hline $\mathrm{h}$ & $0.556 \pm 0.03$ & $0.423 \pm 0.01$ & $0.506 \pm 0.01$ & $0.368 \pm 0.02$ \\
$2 \mathrm{~h}$ & $0.748 \pm 0.03$ & $0.65 \pm 0.02$ & $0.665 \pm 0.01$ & $0.538 \pm 0.03$ \\
$3 \mathrm{~h}$ & $0.865 \pm 0.03$ & $0.753 \pm 0.02$ & $0.746 \pm 0.02$ & $0.636 \pm 0.01$ \\
$4 \mathrm{~h}$ & $0.946 \pm 0.02$ & $0.805 \pm 0.03$ & $0.803 \pm 0.01$ & $0.651 \pm 0.006$ \\
$5 \mathrm{~h}$ & $0.998 \pm 0.03$ & $0.788 \pm 0.04$ & $0.813 \pm 0.009$ & $0.63 \pm 0.01$
\end{tabular}

${ }^{a}$ Values are mean of $6 \pm$ S.D

functional group respectively, are also present in their PM (Fig. 9) with minor peak shifting due to some weak Van der Waals forces [19]. The hydrogen bonding was conformed by shifting of characterstic peak of nonbonded hydrogen of BZ from 3609-3794 to 3405. The $\mathrm{C}=\mathrm{O}$ stretch of carbonyl group for $\mathrm{AN}$ at 1677 and for $\mathrm{BZ}$ at 1684 was shifted to 1624 due to homosynthonic interaction between the drug and coformer [20]. The characteristic peak present in the XRD spectra of AN (Fig. 11) and BZ (Fig. 12) is absent in the XRD spectrum of CCs. There are numerous newer peaks are present which also differ from characteristic peaks present in PM (Fig. 13) of drug and coformer [21]. The homosynthon formation between $\mathrm{OH}-\mathrm{O}$ and $\mathrm{O}-\mathrm{OH}$ present at carboxylic acid of both drug and coformer. Due to hydrogen bonding between carboxylic acids of drug and coformer, newer crystal structure has been generated with different crystalline properties. There are minor changes in relative intensity of characteristic peaks in PM, which may be the resultant of some minor interaction between both components during the mixing process to make PM. The outcomes of the in vitro drug release study revealed an increased dissolution profile of CCs compared to AN and marketed formulation (Fig. 15). As AN is a BCS class II drug, so on the basis of dissolution study, we conclude that cocrystallization of BCS class II drugs could improvise their dissolution profile. The in vivo antiinflammatory activities of CCs were found to have an effect in a dose-dependent manner (Table 7). There was a gradual increase in edema paw volume of rats in the control group. However, in the AN group $(100 \mathrm{mg} / \mathrm{kg})$, half dose of CCs $(50 \mathrm{mg} / \mathrm{kg})$ and full dose of the CC group $(100 \mathrm{mg} / \mathrm{kg})$ showed a significant reduction in the edema paw volume (Fig. 17).

\section{Conclusion}

Herein, AN and BZ CCs have been synthesized successfully in a fixed stochiometric ratio (1:2) by using the solvent evaporation technique. The interaction of drug and coformer was found to be via hydrogen bonding between the carboxylic acid of both components. The CCs exhibited an improved dissolution profile and enhanced in vivo carrageenan-induced paw edema model based on anti-inflammatory activity compared to parent pure drug. Thus, the cocrystallization of AN provides another approach to the development of products having better physicochemical properties and higher pharmaceutical characteristics compared to parent molecules. Further deep investigations of in vitro and in vivo correlation studies are required for better understanding of this approach.

\section{Supplementary information}

Supplementary information accompanies this paper at https://doi.org/10. 1186/s43094-020-00052-y.

Additional file 1. The ARRIVE checklist.

\section{Abbreviations}

AN: Aspirin; CC: Cocrystals; BZ: Benzoic acid; UV: Ultraviolet; PM: Physical mixture; XRD: X-ray diffraction; CSD: Cambridge Structure Database;

API: Active pharmaceutical ingredient; DSC: Differential scanning calorimetry; FT-IR: Fourier transformation infrared spectroscopy; COSMOS-RS: Conductorlike screening model for real solvent

\section{Acknowledgements}

The authors want to thank the Department of Pharmaceutical Sciences, Maharishi Dayanand University, Rohtak, for providing the facilities to conduct this research work.

\section{Authors' contributions}

$\mathrm{BD}$ conducted all the experimentation, writing and editing work. MC supervised all the in vivo anti-inflammatory studies. VB supervised all the in vitro work including dissolution studies and interpretation of analytical data. All authors read and approved the final manuscript.

\section{Funding}

Not applicable

Availability of data and materials

Data and material are available upon request.

\section{Ethics approval}

The animal experiments complied with the ARRIVE guidelines and carried out in accordance with the committee formulated for the 'Breeding of and Experiments on Animals (Control and Supervision) Rules, 1998', which were amended in 2001 and then in 2006 and associated guidelines, for animal experiments. The study was approved by the Institutional Animals Ethics committee [1767/GO/Re/S/14/CPCSEA; dated: August 31, 2017]. The authors have obtained written informed consent to use the animals in the study from the owner of the animals. An ARRIVE checklist has been attached as a separate file regarding the ethics approval and consent to participate.

Consent for publication

Not applicable 


\section{Competing interests}

The authors declare that there is no competing interest.

\section{Author details}

'Department of Pharmaceutical Sciences, Maharshi Dayanand University, Rohtak 124001, India. ${ }^{2}$ University Institute of Pharmaceutical Sciences, Kurukshetra University, Kurukshetra 136119, India.

Received: 28 February 2020 Accepted: 2 July 2020

Published online: 14 July 2020

\section{References}

1. Trask AV (2007) An overview of pharmaceutical cocrystals as intellectual property. Mol Pharm 4(3):301-309. https://doi.org/https://doi.org/10.1021/ mp070001z

2. Kale DP, Zode SS, Bansal AK (2016) Challenges in translational development of pharmaceutical cocrystals. J Pharm Sci 2:1-14. https://doi.org/10.1016/j. xphs.2016.10.021

3. Childs SL, Hardcastle KI (2007) Cocrystals of piroxicam with carboxylic acids. Cryst Growth Des 7(7):1291-1204. https://doi.org/10.1021/cg060742p

4. Maclagan TJ (1876) The treatment of acute rheumatism by salicin. Lancet 3: 342-83, 1876. DOI: https://doi.org/10.1001/archinte.1958.00260170153016

5. Ruder EH, Laiyemo AO, Graubard BI, Hollenbeck AR, Schatzkin A, Cross AJ (2011) Non-steroidal anti-inflammatory drugs and colorectal cancer risk in a large, prospective cohort. Am J Gastroenterol 106:1340-1350. https://doi. org/10.1038/ajg.2011.38

6. Chaudhari FM, Puttewar TY, Patil RY (2015) Solubility enhancement of aspirin by solid dispersion method. Int J Pharm Pharm Res 5(1):208-218

7. Padrela L, Rodrigues MA, Tiago J, Velaga SP, Matos HA, de Azevedo EG (2014) Tuning physicochemical properties of theophylline by cocrystallization using the supercritical fluid enhanced atomization technique. J Supercrit Fluids 86:129-136. https://doi.org/10.1016/j.supflu. 2013.12.011

8. Haeria A, Ismail NI (2015) Characterization and dissolution test of aspirinnicotinamide cocrystal. Int J PharmaTech Res 8(10):166-170

9. Sathisaran I, Dalvi SV (2018) Engineering cocrystals of poorly water-soluble drugs to enhance dissolution in aqueous medium. Pharmaceutics 10(108): 3-74. https://doi.org/10.3390/pharmaceutics10030108

10. Swapna B, Maddileti D, Nangia A (2014) Cocrystals of the tuberculosis drug isoniazid: polymorphism, isostructurality, and stability. Cryst growth des 14 : 5991-05. Doi: dx.doi.org/https://doi.org/10.1021/cg501182t

11. Suresh K, Minkov VS, Namila KK, Derevyannikova E, Losev E, Nangia A, Boldyreva EV (2015) Novel synthons in sulfamethizole cocrystals: structure -property relations and solubility. Cryst Growth Des 15:3498-3410. https:// doi.org/10.1021/acs.cgd.5b00587

12. Kumar S, Nanda A (2017) Pharmaceutical cocrystals: an overview. Indian J Pharm Sci 79(6):858-871. https://doi.org/10.4172/pharmaceutical-sciences. 1000302

13. United States Pharmacopeia and National Formulary (2016) Rockville, MD: United States Pharmacopeial Convention.

14. Douroumis D, Ross SA, Nokhodchi A (2017) Advanced methodologies for cocrystal synthesis Dennis. Adv Drug Deliv Rev 117:178-195. https://doi.org/ 10.1016/j.addr.2017.07.008

15. Raghuram Reddy Kothur AS, Swetha NPB (2012) An outline of crystal engineering of pharmaceutical co-crystals and applications: a review. Int J Pharm Res Dev 4(974):84-92

16. Chaudhary A, Nagaich U, Gulati N, Sharma VK, Khosa RL (2012) Enhancement of solubilization and bioavailability of poorly soluble drugs by physical and chemical modifications: a recent review. J Adv Pharm Educ Res 2(1):32-67. https://doi.org/10.1016/S0040-6031(02)00451-3

17. Jacob JN, Badyal DK, Bala S (2013) Evaluation of the in vivo antiinflammatory and analgesic activity of a highly water-soluble aspirin conjugate. Basic Clin Pharmacol Toxicol 112:171-174. https://doi.org/10. 1111/bcpt.12006

18. Babuselvam M, Ravikumr S, Farook KAM, Abideen S, Mohamed MP, Uthiraselvam M (2012) Evaluation of anti-inflammatory and analgesic effects on the extracts of different parts of Excoecaria agallocha L. J Appl Pharm Sci 2(9):108-112. https://doi.org/10.7324/JAPS.2012.2921

19. Brahamdutt CM, Kumar S, Bhatia M, Budhwar V (2016) Formulation and invitro evaluation of sustained release tropicamide loaded chitosan nanoparticles for ocular drug delivery. Int Res J Pharm 7(10):27-35. https:// doi.org/10.7897/2230-8407.0710118

20. Cheney ML, Weyna DR, Shan N, Hanna M, Wojtas L, Zaworotko MJ (2011) Coformer selection in pharmaceutical cocrystal development: a case study of a meloxicam aspirin cocrystal that exhibits enhanced solubility and pharmacokinetics. J Pharm Sci 6(100):2172-2181. https://doi.org/10.1002/jps. 22434

21. Raghuram M, Alam MS, Prasad M, Khanduri CH (2014) Pharmaceutical cocrystal of prulifloxacin with nicotinamide. Int J Pharm Pharm Sci 6(10): 180-184

\section{Publisher's Note}

Springer Nature remains neutral with regard to jurisdictional claims in published maps and institutional affiliations.

\section{Submit your manuscript to a SpringerOpen ${ }^{\circ}$ journal and benefit from:}

- Convenient online submission

- Rigorous peer review

- Open access: articles freely available online

- High visibility within the field

- Retaining the copyright to your article

Submit your next manuscript at $\boldsymbol{\nabla}$ springeropen.com 